\title{
$\mathrm{BMC}$
}

Cell Biology

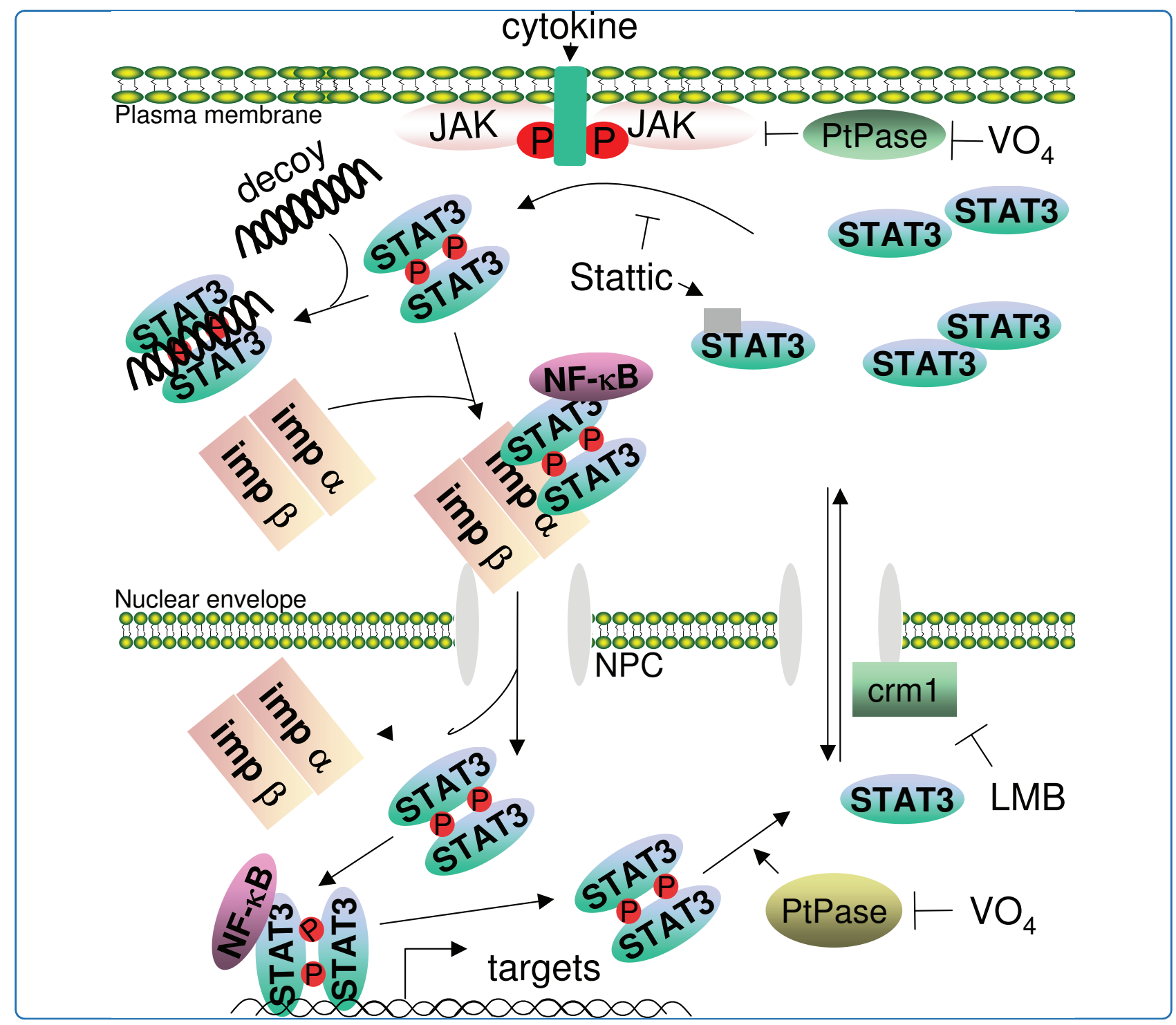

\section{A STAT3-decoy oligonucleotide induces cell death in a human colorectal carcinoma cell line by blocking nuclear transfer of STAT3 and STAT3- bound NF-KB}

Souissi et al. 


\title{
A STAT3-decoy oligonucleotide induces cell death in a human colorectal carcinoma cell line by blocking nuclear transfer of STAT3 and STAT3- bound NF- $\kappa \mathrm{B}$
}

Inès Souissi ${ }^{1,2}$, Imen Najjar ${ }^{6,7}$, Laurent Ah-Koon ${ }^{1,2}$, Pierre Olivier Schischmanoff ${ }^{1,2,3 \dagger}$, Denis Lesage ${ }^{1,2 \dagger}$, Stéphanie Le Coquil ${ }^{1,2}$, Claudine Roger ${ }^{4}$, Isabelle Dusanter-Fourt ${ }^{6,7}$, Nadine Varin-Blank ${ }^{1,2}$, An Cao ${ }^{8}$, Valeri Metelev ${ }^{5}$, Fanny Baran-Marszak ${ }^{1,2,4}$ and Remi Fagard ${ }^{1,2,3^{*}}$

\begin{abstract}
Background: The transcription factor STAT3 (signal transducer and activator of transcription 3 ) is frequently activated in tumor cells. Activated STAT3 forms homodimers, or heterodimers with other TFs such as NF- $\kappa$ B, which becomes activated. Cytoplasmic STAT3 dimers are activated by tyrosine phosphorylation; they interact with importins via a nuclear localization signal (NLS) one of which is located within the DNA-binding domain formed by the dimer. In the nucleus, STAT3 regulates target gene expression by binding a consensus sequence within the promoter. STAT3-specific decoy oligonucleotides (STAT3-decoy ODN) that contain this consensus sequence inhibit the transcriptional activity of STAT3, leading to cell death; however, their mechanism of action is unclear.

Results: The mechanism of action of a STAT3-decoy ODN was analyzed in the colon carcinoma cell line SW 480. These cells' dependence on activated STAT3 was verified by showing that cell death is induced by STAT3-specific siRNAs or Stattic. STAT3-decoy ODN was shown to bind activated STAT3 within the cytoplasm, and to prevent its translocation to the nucleus, as well as that of STAT3-associated NF- $\kappa$ B, but it did not prevent the nuclear transfer of STAT3 with mutations in its DNA-binding domain. The complex formed by STAT3 and the STAT3-decoy ODN did not associate with importin, while STAT3 alone was found to co-immunoprecipitate with importin. Leptomycin $B$ and vanadate both trap STAT3 in the nucleus. They were found here to oppose the cytoplasmic trapping of STAT3 by the STAT3-decoy ODN. Control decoys consisting of either a mutated STAT3-decoy ODN or a NF- $\kappa$ Bspecific decoy ODN had no effect on STAT3 nuclear translocation. Finally, blockage of STAT3 nuclear transfer correlated with the induction of SW 480 cell death.

Conclusions: The inhibition of STAT3 by a STAT3-decoy ODN, leading to cell death, involves the entrapment of activated STAT3 dimers in the cytoplasm. A mechanism is suggested whereby this entrapment is due to STAT3decoy ODN's inhibition of active STAT3/importin interaction. These observations point to the high potential of STAT3-decoy ODN as a reagent and to STAT3 nucleo-cytoplasmic shuttling in tumor cells as a potential target for effective anti-cancer compounds.
\end{abstract}

\footnotetext{
* Correspondence: remi.fagard@avc.aphp.fr

† Contributed equally

${ }^{1}$ INSERM, Unité 978, Bobigny, France

Full list of author information is available at the end of the article
} 


\section{Background}

STAT3 belongs to the signal transducers and activators of transcription (STATs) family of transcription factors (TFs) [1]. STAT3 is activated in response to several cytokines and growth factors, including IL-6, epidermal growth factor (EGF), and interferon (IFN) $\alpha$; STAT3 is also weakly activated in response to other cytokines, including IFN $\gamma$. Activation of STAT3 results from the phosphorylation of tyrosine 705 , mediated by Janus Kinases (JAK), which are associated to cytokine receptors, and also by the Src and Abelson (Abl) families of protein tyrosine kinases [2]. STAT3 is also phosphorylated on serine 727 , sometimes resulting in its activation. Following phosphorylation, STAT3 dimerizes and enters the nucleus by interacting with nuclear import proteins [3] of the karyopherin/importin family [4]. The importins interact with nuclear localization signals (NLS), one of which is located within the DNA binding domain (DBD) of STAT3 and is thought to be the most efficient $[3,5]$. Once in the nucleus, STAT3 activates the transcription of its target genes, including cyclin D1, survivin, VEGF, c-myc, Bcl-xL, and Bcl2 (see [6] for review). Once released from its DNA targets, STAT3 is dephosphorylated in the nucleus [7] and exported to the cytoplasm by a CRM1-dependent process [8]. STAT3 has been described as a key regulator of cell survival and proliferation [9]; its constitutive activation has been observed in many human tumors, including colon, breast, lung, pancreas and prostate cancers, melanoma, head and neck squamous carcinoma, multiple myeloma, mantle cell lymphoma, and glioma [10,11]. In addition, substituting amino acids located at the STAT3 dimer interface for cysteines yielded a stabilized STAT3 dimer that was able to induce a pseudotransformed phenotype [12]. Thus, its constitutive activation in tumor cells points to STAT3 as a valuable target for attacking tumor cells. Furthermore, despite its essential role in development [13], STAT3 is not essential for the functioning of mature cells [14]. Some STAT3 inhibitors are not specific, such as curcumin [15]. In contrast, Stattic, which prevents STAT3 dimerization by specifically interacting with its SH2 domain [16], is highly specific, and efficiently induces tumor cell death $[16,17]$. Despite its frequent involvement in cancer, which makes it a highly valuable target for inducing tumor cell death, STAT3 still lacks more specific inhibitors. Besides the SH2 domain, another potential target for highly selective STAT3 inhibitors is its DBD, since it selectively recognizes and binds DNA motifs in target genes. Decoy oligonucleotides (decoy ODNs) containing the TFs' DNA binding consensus sequences selectively inhibit them by binding to the DBD [18]. They can induce, in vitro, the death of tumor cells whose growth depends on these
TFs [19]. This has notably been shown for several TFs, including NF- $\kappa \mathrm{B}[20,21]$ and STAT3 [17,22-24]. STAT3-decoy ODN efficiently induced cell death in mouse xenografts of a head and neck squamous cell carcinoma [25]. One limitation of STAT3-decoy ODN is that despite the different functions of STAT1 and STAT3 in the cell, they recognize very similar DNA targets [26], with the result that STAT3-decoy ODN can inhibit either one or the other. For example, in the colon carcinoma cell line SW 480, the constitutive activation of STAT3 contributes to cell survival; its inhibition by STAT3-decoy ODN induces cell death. However, the ODN also blocks IFN $\gamma$-mediated cell death through STAT1 activation in the same cell line [17]. The actual mechanism through which decoy ODNs inhibit TFs is still unclear. Of the many studies demonstrating decoy ODN-mediated inhibition of TFs such as E2F, NF- $\kappa$ B [27], CRE and AP1 [28], none have specifically investigated the subcellular localization required for decoy ODNs to exercise their inhibitory action. A study on AP1 suggested that nuclear entry is required for decoy ODNs to inhibit targeted TFs [29]. Another study showed that a decoy ODN engineered to contain a nuclear localization signal (NLS) could enter the nucleus and efficiently inhibit p53 [30]. It is not clear yet whether these requirements depend on cellular systems or on the TFs that are targeted, since other studies have found that decoy ODNs did not have to enter the nucleus to exert their inhibitory effect $[17,21]$. In order to assess their possible use in human cancer, it will be important to understand the mechanism through which the decoy ODNs interfere with TFs and to determine whether nucleo-cytoplasmic shuttling is impaired. In the case of STAT3, constitutive shuttling from cytoplasm to nucleus has been demonstrated [8,31]. Furthermore, STAT3's localization seems to be predominantly nuclear [32], indicating that the shuttling mechanism could be a promising target for achieving effective STAT3 inhibition, as previously suggested [33]. Decoy ODNs' mechanism of action on STAT3 was therefore studied to determine whether nucleo-cytoplasmic shuttling was impaired, leading to STAT3 inhibition. Finally, since STAT3 has been reported to interact and synergize with NF- $\kappa$ B [34] in tumor cells [35], this study also addresses the functional interplay of NF- $\kappa \mathrm{B}$ and decoy ODN.

\section{Methods}

\section{Cell culture and reagents}

SW 480 (colon adenocarcinoma) and MCF-7 (breast cancer) cell lines were grown in DMEM (GibcoBRL, Life technologies, Cergy-Pontoise, France), supplemented with 10\% FCS (Lonza, Levallois-Perret, France) 100 U/ $\mathrm{mL}$ penicillin, $10 \mu \mathrm{g} / \mathrm{mL}$ streptomycin (GibcoBRL), 1 
mM sodium pyruvate (GibcoBRL), MEM vitamins $100 \times$ (GibcoBRL) and $5 \mu \mathrm{g} / \mathrm{mL}$ plasmocin (Cayla InvivoGen, Toulouse, France). The KG-1 cells were grown in 10\% FCS supplemented IMDM medium (GibcoBRL). For the STAT3 overexpression experiments the plasmid PLZst3 $\alpha$ was used. The STAT3 DNA binding domain (DBD)-mutant containing two mutations in the DBD that completely prevented DNA binding but allowed dimerization and nuclear entry, was a kind gift from Dr. C. Horvath (Northwestern University, Chicago, USA) [36]. For some experiments, cells were treated with TNF $\alpha(20$ ng/ml) (Sigma-Aldrich, Montigny le Bretonneux, France). To enhance STAT3 activation, cells were treated for $1 \mathrm{hr}$ with IL-6 (50 ng/ml) (Sigma). Sodium orthovanadate $(100 \mu \mathrm{M})$ (stock solution: $100 \mathrm{mM})$ was from Fischer (Illkirch, France), leptomycin B (LMB) (10 $\mathrm{ng} / \mathrm{ml}$ ) was from Sigma-Aldrich.

\section{RNA silencing}

For cell infection with lentiviral shRNA, a set of two STAT1-targeting shRNAs that has previously been found to reduce the expression of STAT1 [37] was used and transduced as previously described [37]. Efficiency of infection was verified by measuring GFP by flow cytometry, and the efficacy of the inhibition of the shRNA's inhibition of STAT1 expression was verified by western blotting using a STAT1-specific antibody (Cell Signaling, Ozyme, St Quentin Fallavier, France).

For siRNA STAT3 silencing, the following double stranded siRNA oligonucleotide, previously shown to suppress STAT3 expression in a colorectal cell line [38], was purchased from Sigma-Aldrich: 5'-AACAUCUGCCUAGAUCGGCUAdTdT-3'; 3'-dTdTGUAGACGGAUCUAGCCGAU-5', along with a universal control set of siRNA (Sigma Aldrich). Cells $\left(10^{5}\right.$ cells/well; density: $60 \%$ ) were transfected using polyethylene imine (PEI) with $10 \mathrm{nM}$ siRNA in culture medium without antibiotics. After $48 \mathrm{~h}$ or $72 \mathrm{~h}$, cells were harvested and analyzed for annexin $\mathrm{V}$ binding by flow cytometry. In control cells, the irrelevant control siRNA was used. All experiments were performed in triplicate.

\section{Preparation of subcellular fractions}

Cells $\left(20 \times 10^{6}\right)$ were resuspended in cell lysis buffer containing $20 \mathrm{mM}$ Hepes $\mathrm{pH} 7.4,1 \mathrm{mM} \mathrm{MgCl} 2,10 \mathrm{mM}$ $\mathrm{KCl}, 0.3 \% \mathrm{NP} 40,0.5 \mathrm{mM}$ DTT, $0.1 \mathrm{mM}$ EDTA and protease inhibitors (CompeteTM, Boerhinger, France), and placed at $4^{\circ} \mathrm{C}$ for $5 \mathrm{~min}$. The lysates were centrifuged at $14000 \mathrm{~g}$ for $5 \mathrm{~min}$ at $4^{\circ} \mathrm{C}$, and the supernatant containing the cytoplasmic fraction was stored in aliquots at $-80^{\circ} \mathrm{C}$. The pellets were resuspended in cell lysis buffer adjusted to $20 \%$ glycerol and $0.35 \mathrm{M} \mathrm{NaCl}$ and placed at $4^{\circ} \mathrm{C}$ for $30 \mathrm{~min}$. After centrifugation at $14000 \mathrm{~g}$ for 5 min at $4^{\circ} \mathrm{C}$, the supernatant, containing the nuclear proteins, was stored at $-80^{\circ} \mathrm{C}$. Protein amounts were determined before use with the micro-BCA protein determination kit (Pierce, Perbio, Brebières, France).

\section{Decoy oligonucleotides}

The STAT3-decoy ODNs used were: $\operatorname{RHN}\left(\mathrm{CH}_{2}\right)_{6}$ CATTTCCCGTAAATCGAAGATTTACGGGAAATG $-\left(\mathrm{CH}_{2}\right)_{3} \mathrm{NHR}$ (hp STAT3-decoy ODN), derived from the serum-inducible element of the human c-fos promoter [39], and $\mathrm{RHN}\left(\mathrm{CH}_{2}\right)_{6}$ - CATTTGCCACAATCGAAGATTGTGGCAAATG - $\left(\mathrm{CH}_{2}\right)_{3} \mathrm{NHR}$ (hairpin STAT3decoy mutated ODN) (Sigma-Proligo) where $\mathrm{R}$ was either $\mathrm{H}$, FITC or biotin. The decoy NF- $\kappa \mathrm{B}-\mathrm{ODN}$ consisted of: $\mathrm{RNH}\left(\mathrm{CH}_{2}\right)_{6}$-CTGGAAAGTCCCTCGAAGAGGGACTTTCCAG- $\left(\mathrm{CH}_{2}\right)_{3} \mathrm{NHR}$ (hairpin decoy NF$\kappa \mathrm{B}-\mathrm{ODN})$ and $\mathrm{RHN}\left(\mathrm{CH}_{2}\right)_{6}$-TGCAGTCACTACGCGAAGCGTAGTGACTGCA- $\left(\mathrm{CH}_{2}\right)_{3} \mathrm{NHR}$ (hairpin scrambled decoy NF- $\kappa$ B-ODN) where $\mathrm{R}$ is either $\mathrm{H}$ or biotin. The synthesis of decoy oligonucleotides with $\mathrm{R}=$ $\mathrm{H}$ has been published elsewhere [17]. For biotin addition, 7-10 nanomoles of the oligodeoxynucleotide bearing 3'- and 5'-aminoalkyl linkers were dissolved in $20 \mu \mathrm{L}$ of $0.1 \mathrm{M} \mathrm{NaHCO}_{3}$. EZ-Link NHS-biotin (Pierce, Rockford, USA) (10 $\mu \mathrm{L}$ of a $65 \mathrm{mM}$ solution in dimethyl sulfoxide) was added, and the mixture was incubated at room temperature for 6-16 h in the dark. Then $25 \mu \mathrm{L}$ of water were added, and the modified oligodeoxynucleotide was separated from the excess of hydrolyzed reagent by two consecutive separations on Micro BioSpin 6 columns following the manufacturer's recommendations. After the second spin, the biotinylated oligodeoxynucleotide was precipitated with ethanol-sodium acetate. In control experiments the previously published decoy NF- $\kappa$ B-ODN [21] was used. In some cases FITClabeled or biotinylated decoy ODNs were obtained from Sigma-Aldrich. Note that the oligonucleotides used for cell death induction, pull-down assays and whole-cell pull-down assays were similar and could be used interchangeably, except that for pull-down biotinylated oligonucleotides had to be used.

\section{Preparation of liposomes}

Liposomes were formulated using a cationic lipid ( $3 \beta$ [N-(N',N',N'-triethylaminopropane)-carbamoyl] cholesterol) iodide (TEAPC-Chol) and neutral colipid dioleoyl phosphatidylethanolamine (DOPE), as previously described [40]. The concentration of cationic lipid was monitored by UV spectroscopy at $226 \mathrm{~nm}$ and the value was used to calculate the charge ratio assuming one positive charge for each cationic lipid molecule.

\section{Gel electrophoresis, western blotting}

Cells were washed in PBS, lysed in sample buffer (50 mM Tris-HCl pH 6.8 (Bio-Rad, Marnes-la-Coquette, 
France), 2\% sodium dodecyl sulfate (SDS) (SigmaAldrich), 20\% glycerol (Prolabo, Fontenay-sous-Bois, France), $1 \mathrm{mM}$ sodium vanadate $\left(\mathrm{Na}_{3} \mathrm{VO}_{4}\right.$, Labosi, Elancourt, France), $1 \mathrm{mM}$ dithiothreitritol (DTT) (Merck, Fontenay Sous Bois, France) and $0.01 \%$ bromophenol blue (Sigma-Aldrich), sonicated and stored at $-70^{\circ} \mathrm{C}$. Proteins $(50 \mu \mathrm{g})$ were separated on SDS-PAGE $(10 \%)$ and transferred onto nitrocellulose membranes; membranes blocked with 5\% dry skimmed milk in TBS were incubated with antibody overnight at $4^{\circ} \mathrm{C}$. Anti-phosphotyrosine $705-$ STAT3 $(1 / 1,000)$, anti-STAT3 (1/ $1,000)$, anti-NF- $\kappa \mathrm{B}$ p50 (1/1,000), anti-NF- $\kappa \mathrm{B}$ p65 (1/ $1,000)$, anti-STAT1 $(1 / 1,000)$, and anti-OCT1 $(1 / 1,000)$ were from Cell Signaling, anti-karyopherin/importin $\alpha$ (1:400) was from Santa Cruz (Tebu-bio, Le Perray en Yvelines, France). Blots were washed in TBS-T, incubated with peroxidase-coupled goat anti-mouse (Santa Cruz, Tebu-bio) or goat anti-rabbit (Upstate, Ozyme) secondary antibody $(1 / 20,000)$ washed in TBS-T and revealed by chemiluminescence (LumiGLO reagent and peroxide; Cell Signaling) and autoradiography (X-Omat $\mathrm{R}$ film; Kodak). When necessary, membranes were stripped with Blot Restore Kit (Chemicon International) and reprobed with anti-actin antibody (Cell Signaling). Prestained molecular weight standards (Fermentas, Saint-Rémy-lès-Chevreuse, France) were used. For the quantification analysis, the bands from at least three separate experiments were scanned using a Chemidoc apparatus (Biorad) and quantification performed using the Quantity One software (Biorad). P-values were calculated using a t test.

\section{Real-time qPCR}

The TaqMan ${ }^{\circledR}$ Gene Expression Cells-to-CT ${ }^{\mathrm{TM}}$ kit (Applied Biosystems, Courtaboeuf, France) was used to extract total RNA and to perform reverse transcription and gene amplification. An Applied Biosystems Custom TaqMan Gene Expression Assay was used; the sequences were chosen to cover exons 5 and 6 to avoid detecting genomic DNA: sense primer: 5 '-ccatcttcatcacactcttcctgtt, antisense primer: 5 '-accaccgaggagaagatcca, 5'-FAM probe: 5-ctacagtgccaccgtcacc. For the TaqMan Gene Expression Assay (Applied Biosystems) ref. Hs00941525_g1 was used. For cyclophilin A (PPIA), used as a reference, the TaqMan Gene Expression Assay, ref. Hs99999904_m1 was used. All steps were performed following the recommendations of the manufacturer. Relative expression levels of each gene were calculated as previously described.

\section{Transfections}

Cells were grown in 4-well plates to a density of $0.510^{6}$ cells $/ \mathrm{mL}$. When the cells reached $50-60 \%$ confluence, they were transfected with STAT3-decoy ODN or the hairpin control decoy ODN ( $2 \mu \mathrm{g}$ corresponding to 400 $\mathrm{nM}$ ) in $150 \mu \mathrm{L}$ of DMEM medium (without SVF) combined with the liposomes ( $2 \mu \mathrm{g}$ of cationic lipid). After 6 $\mathrm{h}$ at $37^{\circ} \mathrm{C}$ in a humidified $5 \% \mathrm{CO}_{2}$ incubator, the cells were placed in fresh serum-containing medium. Expression was analyzed after $48 \mathrm{~h}$. In other cases, transfection was performed using polyethyleneimine (PEI, SigmaAldrich), with an ODN-to-polyethyleneimine ratio of $1: 1$.

\section{Flow cytometry, cell viability, immunocytochemistry}

To measure cell death, cells were resuspended in annexin V-binding buffer, incubated with $5 \mu \mathrm{L}$ of propidium iodide (BD Pharmingen, Morangis, France) and subjected to flow cytometry analysis, using a BD FACS Canto II Flow Cytometer. Cell viability was also assessed using the trypan-blue exclusion method with a V-cell counter (Beckmann, Villepinte, France)

For immunocytochemistry, cells were grown in 8-well plates (lab-tek, Nunc, Rochester, USA) to a density of $0.510^{6}$ cells $/ \mathrm{mL}$. At $50-60 \%$ confluence, cells were transfected with the FITC-labeled STAT3-decoy ODN or the FITC-labeled mutated STAT3-decoy ODN. After $48 \mathrm{~h}$ the cells were washed in $\mathrm{NaCl}$-phosphate buffer, fixed in $3.7 \%$ formaldehyde for $15 \mathrm{mn}$, permeabilized in $0.1 \%$ Triton X-100 for $15 \mathrm{mn}$ and blocked in 5\% FCS, $0.1 \%$ Tween in $\mathrm{NaCl}$-phosphate buffer for $1 \mathrm{~h}$. Cells were stained with anti-STAT3 antibody (Cell Signaling) (dilution: 1:100) or anti- phosphotyrosine 705-STAT3 antibody (Cell Signaling) (1:100) for $2 \mathrm{~h}$ and Alexa Fluor 546-labeled secondary antibody (Invitrogen) (1:200) for $90 \mathrm{mn}$. After counterstaining with 4', 6'- diamidino-2phenylindole (DAPI) coverslips were mounted onto glass slides with Vectashield (Vectorlabs, Clinisciences, Montrouge, France). Fluorescence images were acquired using a Zeiss Axioplan2 Deconvolution microscope (Carl Zeiss, Le Pecq, France) and analyzed with Metafer4 (Metasystems, Altlussheim, Germany).

\section{Oligodeoxynucleotide pull-down}

Nuclear protein extracts were obtained as follows: 20 million cells were resuspended in lysis buffer $(20 \mathrm{mM}$ Hepes, pH 7.4, $1 \mathrm{mM} \mathrm{MgCl} 2,10 \mathrm{mM} \mathrm{KCl}, 0.3 \% \mathrm{NP} 40$, $0.5 \mathrm{mM}$ dithiothreitol, $0.1 \mathrm{mM}$ EDTA, protease inhibitors: Compete ${ }^{\mathrm{TM}}$, Boerhinger) at $4^{\circ} \mathrm{C}$ for $20 \mathrm{~min}$. The lysates were centrifuged at $14000 \times \mathrm{g}$ for $5 \mathrm{~min}$ at $4^{\circ} \mathrm{C}$, and the supernatants containing the cytoplasmic proteins were discarded. The pellets were resuspended in the cell lysis buffer adjusted with $20 \%$ glycerol and 0.35 $\mathrm{M} \mathrm{NaCl}$ for $30 \mathrm{~min}$ at $4^{\circ} \mathrm{C}$. After centrifugation at 14 $000 \times \mathrm{g}$ for $5 \mathrm{~min}$ at $4^{\circ} \mathrm{C}$, the supernatants were stored at $-80^{\circ} \mathrm{C}$. For pull-down assays, $100-200 \mu \mathrm{g}$ of nuclear protein extracts were incubated for $30 \mathrm{~min}$ at $4{ }^{\circ} \mathrm{C}$ in binding buffer (1\% NP40, 50 mM Hepes, pH 7.6, 140 
$\mathrm{mM} \mathrm{NaCl})$ containing salmon sperm DNA ( $1 \mu \mathrm{g} /$ assay) and $1 \mu \mathrm{g}$ of the biotinylated hairpin decoy ODN or the mutated decoy ODN. The complexes were captured by incubation with $50 \mu \mathrm{l}$ of avidin-Sepharose beads (neutravidin, Pierce) for $2 \mathrm{~h}$ at $4^{\circ} \mathrm{C}$. For in-cell decoy ODN pull-down assays, the cells were first transfected with STAT3-decoy ODN or its mutated equivalent, as described under oligonucleotide transfection (see above), and then processed as above by cell lysis and recovery on avidin-Sepharose beads. After extensive washing with binding buffer, complexes were separated on SDS-polyacrylamide (8\%) gel, and subjected to immunoblotting using an anti-STAT3 antibody (Cell Signaling). Results were analyzed by chemiluminescence (LumiGLO, Cell Signaling) and autoradiography (X-Omat R, Kodak).

\section{Antibody co-immunoprecipitation}

For antibody pull-down assays, 20 million cells were lyzed and resuspended in lysis buffer (20 mM Hepes, $\mathrm{pH}$ 7.4, $1 \mathrm{mM} \mathrm{MgCl}$, $10 \mathrm{mM} \mathrm{KCl,} \mathrm{1 \%} \mathrm{NP40,} 0.5 \mathrm{mM}$ dithiothreitol, $0.1 \mathrm{mM}$ EDTA, $1 \mathrm{mM}$ orthovanadate, protease inhibitors; Compete ${ }^{\mathrm{TM}}$, Boerhinger) at $4^{\circ} \mathrm{C}$ for 5 min. The lysates were centrifuged at $14000 \times$ g for 5 $\min$ at $4^{\circ} \mathrm{C}$, and the supernatants containing the cytoplasmic proteins were either used immediately or stored at $-80^{\circ} \mathrm{C}$. For the immunoprecipitations, 200 to $400 \mu \mathrm{g}$ protein was supplemented with albumin-saturated protein G-agarose (Boehringer); after centrifugation $(8000 \times$ g, $5 \mathrm{~min}$ ), the pellet was discarded and the supernatant conserved. Antibody was added (STAT3: 1:100; karyopherin, Santa-Cruz: 1:40) and incubation continued overnight at $4^{\circ} \mathrm{C}$. Samples were then supplemented with albumin-saturated protein G-agarose and incubated for $1 \mathrm{~h} 30 \mathrm{~m}$. The agarose beads were washed three times with TBS and once with TBS-T, and resuspended in SDS-sample buffer. Gel separation and western blotting were performed as described above.

\section{Results}

\section{Survival of SW 480 colon carcinoma cells requires activated STAT3}

STAT3 is activated in colon carcinoma and in the colon carcinoma cell line SW $480[17,41]$. In SW 480 cells transfected with specific STAT3 siRNA, the expression of STAT3 was strongly reduced (Figure 1A) and the number of annexin $\mathrm{V}$-positive cells was significantly increased in comparison to cells treated with control siRNA (Figure 1B). STAT3 tyrosine 705 phosphorylation was detected (Figure 1C) as previously reported [17,41]. Pull-downs with biotinylated ODN were performed, followed by western blotting with anti-STAT3 antibody. This method is analogous to gel retardation assays, and revealed that STAT3 is activated. ODN-bound activated STAT3 was detected in nuclear extracts from untreated
(Figure 1D, lane 2) and IL-6-treated cells (lane 4); cytoplasmic STAT3 only weakly bound the biotinylated ODN (Figure 1D, lanes 1 and 3). Treatment of cells with the STAT3 inhibitor Stattic $(20 \mu \mathrm{M})$, known to inhibit STAT3 phosphorylation and dimerization [16], inhibited the nuclear translocation of STAT3 in SW 480 cells (Figure 1E, lane 4, see also figure threeD), as previously shown in other cell lines [16]; this correlated with induction of cell death (Figure 1F).

\section{Cytoplasmic sequestration of STAT3 and phospho-STAT3 by STAT3-decoy ODN}

The subcellular distribution of STAT3-decoy ODN in SW 480 cells was shown by fluorescence microscopy to be essentially cytoplasmic (see [additional file 1], and figures $2 \mathrm{~B}$ and $2 \mathrm{C}$ ). Immunofluorescence microscopy analyzis of the subcellular localization of phosphoSTAT3 in untreated SW480 cells showed that it was essentially nuclear (Figure 2A), but following STAT3decoy ODN treatment it became mostly cytoplasmic (Figure 2B), this was not observed when using mutated STAT3-decoy ODN (Figure 2C). Pull-down experiments within cells transfected with biotinylated STAT3-decoy ODN followed by western blotting showed that phospho-STAT3 interacted with STAT3-decoy ODN (Figure $2 \mathrm{D})$. In these experiments, the binding of phosphoSTAT3 to the STAT3-decoy ODN was blocked by the treatment of cells with Stattic (10 and $20 \mu \mathrm{M})$, known to prevent STAT3 dimer formation [16], indicating that the STAT3-decoy ODN binds activated STAT3 dimers (Figure 2D). Total STAT3 was almost exclusively nuclear in untreated cells (Figure 3A), but after treatment with STAT3-decoy ODN it became cytoplasmic (Figure $3 \mathrm{~B}$ ). This was not observed when using mutated STAT3-decoy ODN (Figure 3C) but was observed when treating cells with Stattic (Figure 3D). Subcellular localization of STAT3 studied by cell fractionnation and western blotting showed that STAT3-decoy ODN efficiently prevented STAT3 nuclear translocation (Figure 3E, lane 4 ), whereas neither a mutated STAT3-decoy ODN (lane $6)$, nor a NF- $\kappa$ B-decoy ODN did so (Figure $3 F$, lane 4). A diagram of the data collected from several experiments illustrates the effect of STAT3-decoy ODN on the nucleo-cytoplasmic distribution of STAT3: in STAT3-decoy ODN-transfected cells nuclear STAT3 consisted of $20 \%$ of the total STAT3 (Figure 3G); conversely, in control-, mutated decoy ODN-, and NF- $\kappa \mathrm{B}-$ decoy ODN-transfected cells, it consisted of $50 \%$ of the total STAT3, suggesting that STAT3-decoy ODN functions by trapping STAT3 within the cytoplasm. Finally, the binding of STAT3 to biotinylated STAT3-decoy ODN within cells was blocked by addition of excess non-biotinylated STAT3-decoy ODN (Figure 3H, and [additional file 2]). 

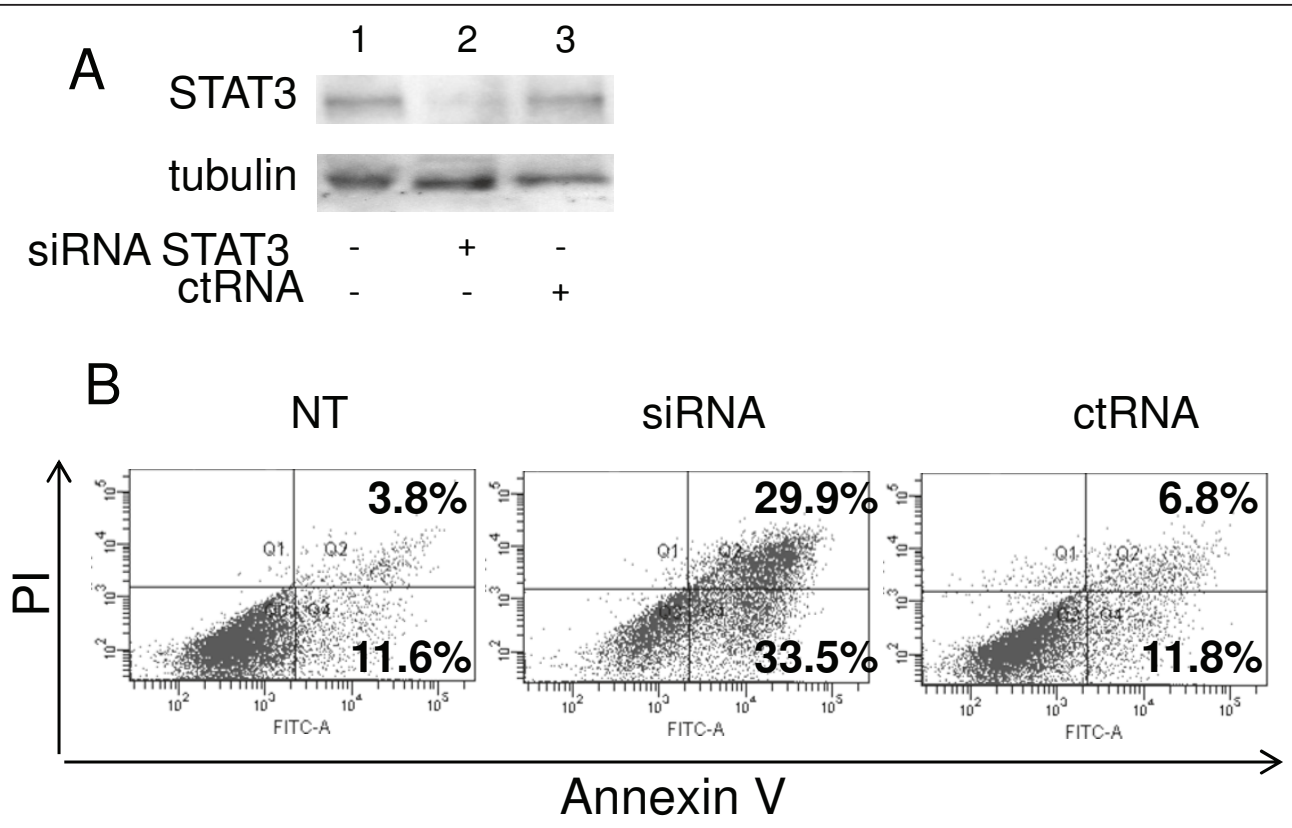

C
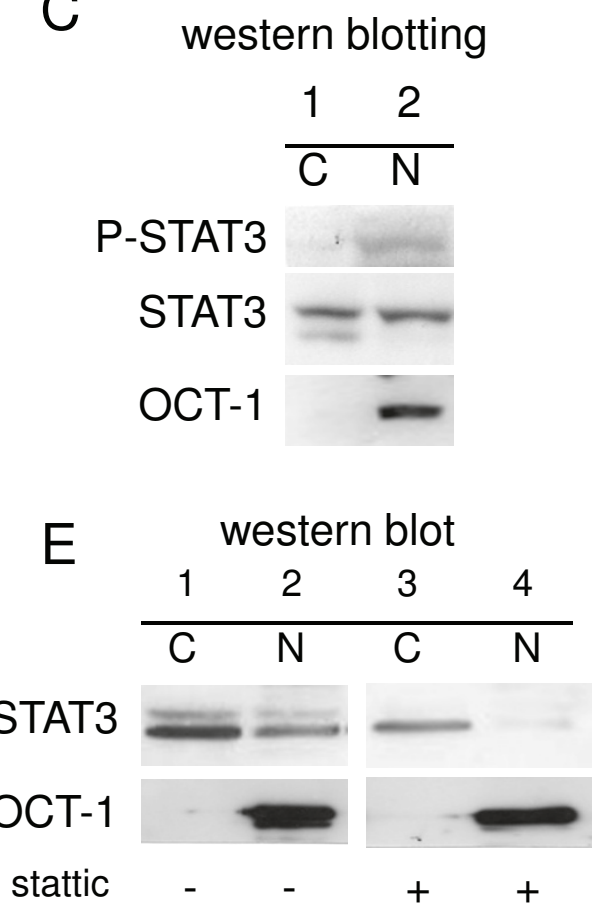

D

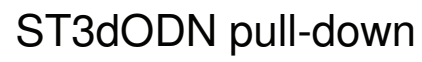

\begin{tabular}{llll}
1 & 2 & 3 & 4 \\
\hline $\mathrm{C}$ & $\mathrm{N}$ & $\mathrm{C}$ & $\mathrm{N}$
\end{tabular}

STAT3

input

(STAT3)

IL-6

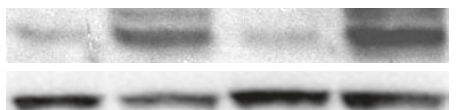

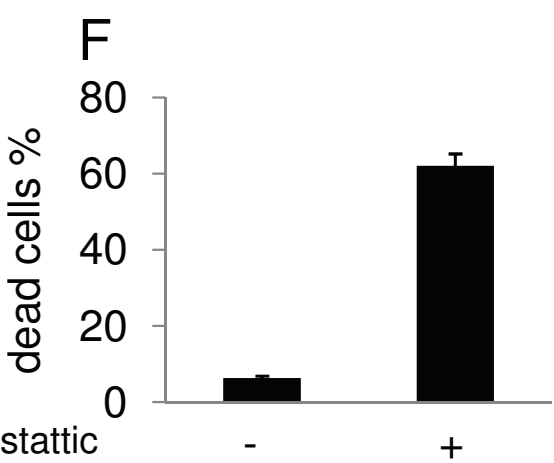

Figure 1 STAT3 activation is required for SW $\mathbf{4 8 0}$ colon carcinoma cell survival. A: Western blotting of STAT3 in cells not transfected with siRNA (lane 1) or transfected with either STAT3 siRNA (lane 2) or control siRNA (lane 3). B: Detection by cytometry of annexin $V$ and propidium iodide (PI)-positive cells in the absence of transfection (NT), or after transfection with STAT3 siRNA (siRNA) or control siRNA (ctRNA). A typical experiment is shown. C: Western blotting of phospho-STAT3 and STAT3 in cytoplasmic (C) and nuclear (N) fractions of non-treated SW 480 cells. OCT-1 was used as nuclear marker control. D: Pull-down with biotinylated STAT3-decoy ODN using cytoplasmic (lanes 1 and 3) and nuclear (lanes 2 and 4) extracts from untreated (lanes 1 and 2) or IL-6-treated (50 ng/ml, $1 \mathrm{~h}$ ) cells (lanes 3 and 4). E: Western blotting of phospho-STAT3 and STAT3 in cytoplasmic (C) and nuclear (N) fractions of non-treated SW 480 cells $(1,2)$ or Stattic-treated cells $(20 \mu M)$. OCT-1 was used as nuclear marker control. F: Measurement of cell death using trypan blue-staining and counting with a V-cell automatic apparatus. Cells were either not treated or treated with Stattic $(20 \mu \mathrm{M}, 48 \mathrm{~h})$. 


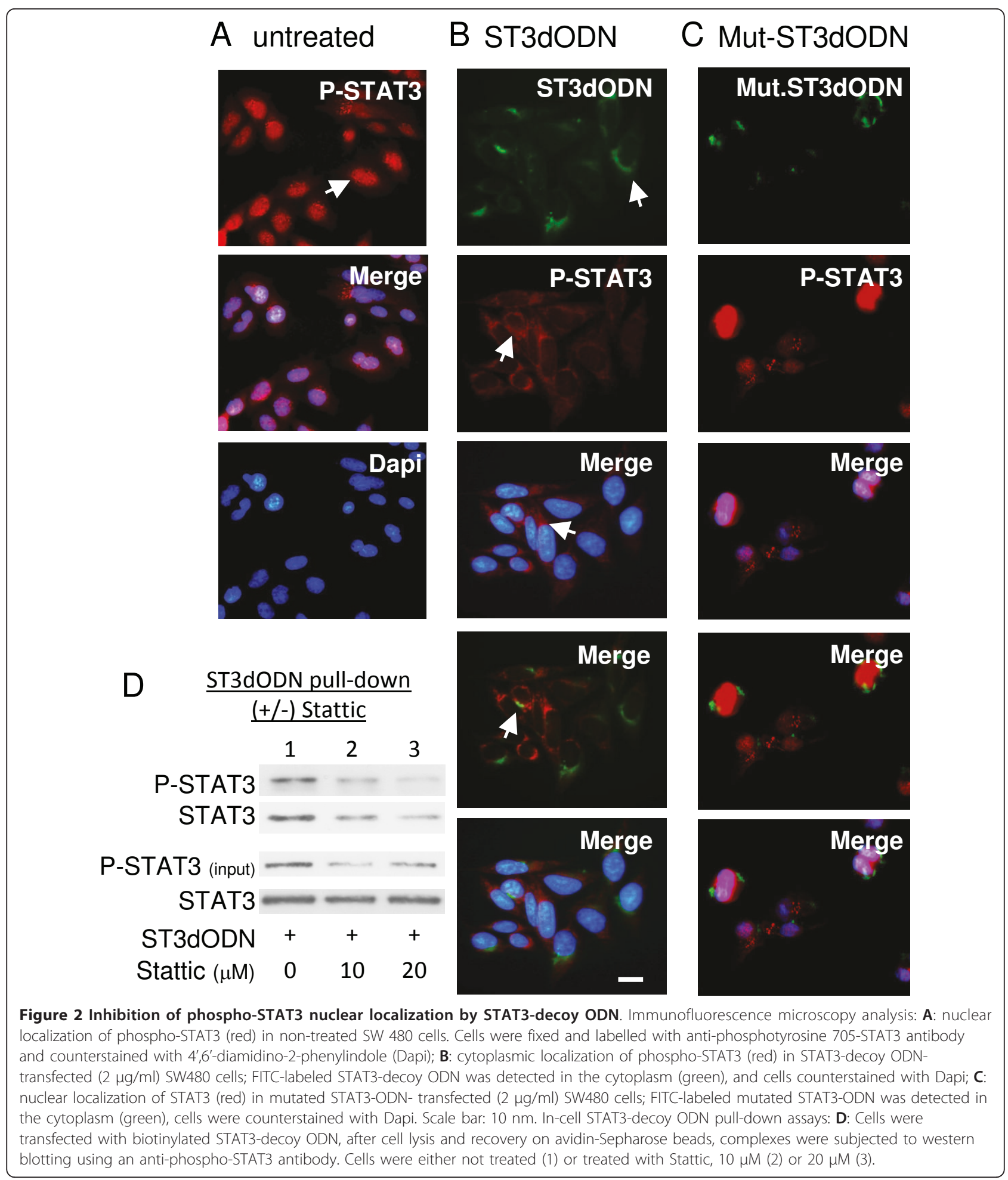

Cytoplasmic sequestration of STAT3 and phospho-STAT3 by STAT3-decoy ODN correlates with STAT3 inhibition and cell death

In STAT3-decoy ODN-transfected SW 480 cells, cell death increased (Figure 4A), as previously shown in these [17] and other cells [22-24]. STAT3-decoy ODN also induced cell death of MCF-7 cells, in which a low but detectable STAT3 activation has been previously observed [42]. However, the STAT3-decoy ODN had no effect on the acute myeloid leukemia cell line KG1, in 

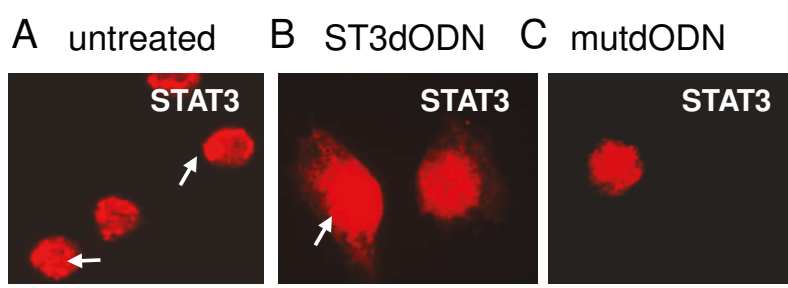

D Stattic
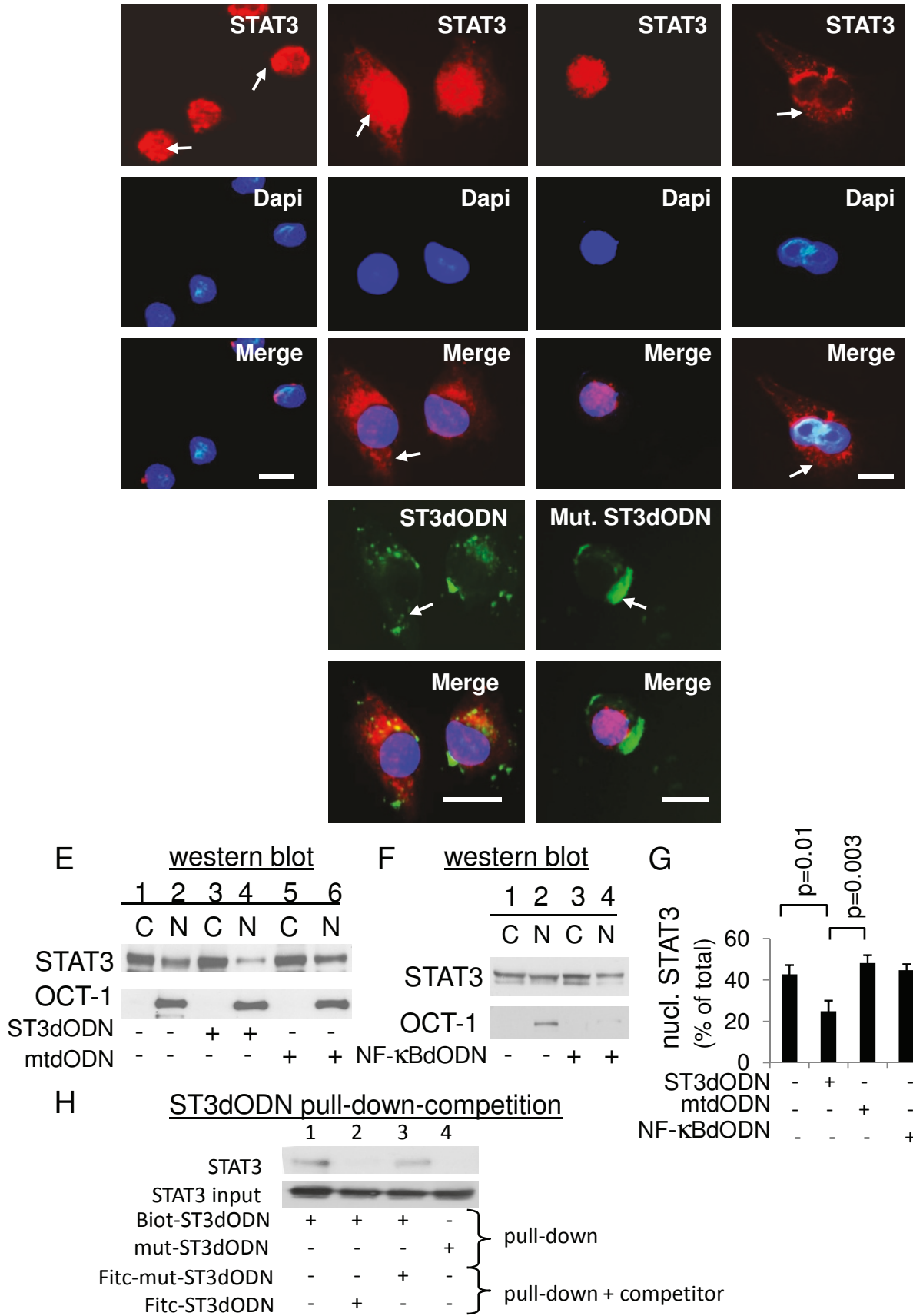

Figure 3 Inhibition of STAT3 nuclear localization by STAT3-decoy ODN. A: Nuclear localization of STAT3 (red) in non-treated SW 480 cells. Cells were fixed and labelled with anti-STAT3 antibody; B: cytoplasmic localization of STAT3 (red) in STAT3-decoy ODN- transfected (2 $\mu \mathrm{g} / \mathrm{ml})$ SW480 cells; FITC-labeled STAT3-decoy ODN was detected in the cytoplasm (green); C: nuclear localization of STAT3 (red) in mutated STAT3ODN- transfected $(2 \mathrm{\mu g} / \mathrm{ml})$ SW480 cells; FITC-labeled mutated STAT3-ODN was detected in the cytoplasm (green); D: cytoplasmic localization of STAT3 in Stattic-treated cells $(20 \mu \mathrm{M})$. Nuclei stained with DAPI. Scale: $10 \mathrm{~nm}$. E: Cells transfected with STAT3-decoy ODN and STAT3 determined in cytoplasm and nucleus: no treatment (1 and 2), STAT3-decoy ODN $2 \mu \mathrm{g} / \mathrm{ml}$ (3 and 4), mutated STAT3-decoy ODN (mtODN) $2 \mu \mathrm{g} / \mathrm{ml}(5 \mathrm{and} 6)$. OCT-1 antibody reprobing to check for cytoplasmic contamination. A typical result is shown. F: Cells were untreated (1 and 2), transfected with decoy NF- $\kappa$ B-ODN (2 $\mu \mathrm{g} / \mathrm{ml})$ (3 and 4), and STAT3 subcellular localization determined. G: Quantitative comparison. In control and mutated STAT3-decoy ODN (mtODN)- or decoy NF- $\kappa$ B-ODN-transfected cells, nuclear STAT3 (expressed as \% of total STAT3, cytoplasmic + nuclear) was 50\%; it was below 20\% in STAT3-decoy ODN-transfected cells. Data from at least three independent experiments. A t test was used to calculate $p$ values, $n>3$. H: Cells transfected with biotinylated STAT3-decoy ODN (1, 2 and 3) or its mutated equivalent (4) and complexes recovered and analyzed as in D; cells co-transfected with competitor: non-biotinylated STAT3-decoy ODN (2) or its mutated equivalent (3). 


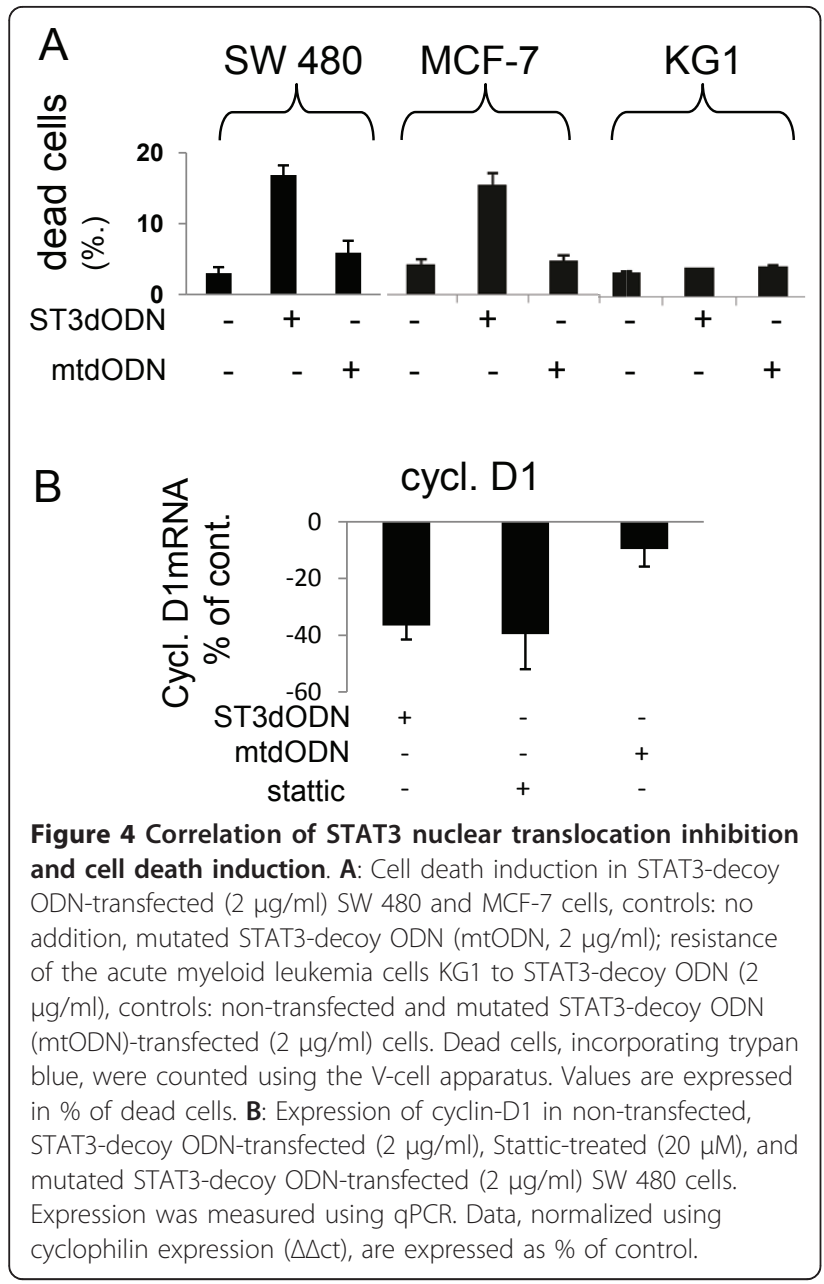

which STAT5, rather than STAT3, is activated [43] (Figure 4A). The mutated STAT3-decoy ODN had no effect in any of the three cell lines (Figure 4A). The STAT3-target cyclin-D1 was analyzed by qPCR in STAT3-decoy ODN-transfected SW 480 cells: reduced cyclin-D1 expression was observed, similar to that observed with Stattic (Figure 4B). This suggests that it is the cytoplasmic trapping of STAT3 by the STAT3decoy ODN which leads to cell death. Since STAT3decoy ODN can also bind STAT1 and prevent STAT1dependent IFN $\gamma$-induced cell death [17], experiments were performed to determine the overall involvement of STAT1 in STAT3-decoy ODN-induced cell death. To this end, STAT1 was silenced using shRNA in the SW 480 cells. As previously described in other cell systems [37], the expression of STAT1 was suppressed by specific shRNA, and not by empty vector; NF- $\kappa$ B and STAT3 expression was unchanged (Figure 5A). In STAT1silenced SW 480 cells, the basal level of dead cells was unchanged. However, STAT3-decoy ODN-induced cell death was suppressed (Figure 5B). There was no effect

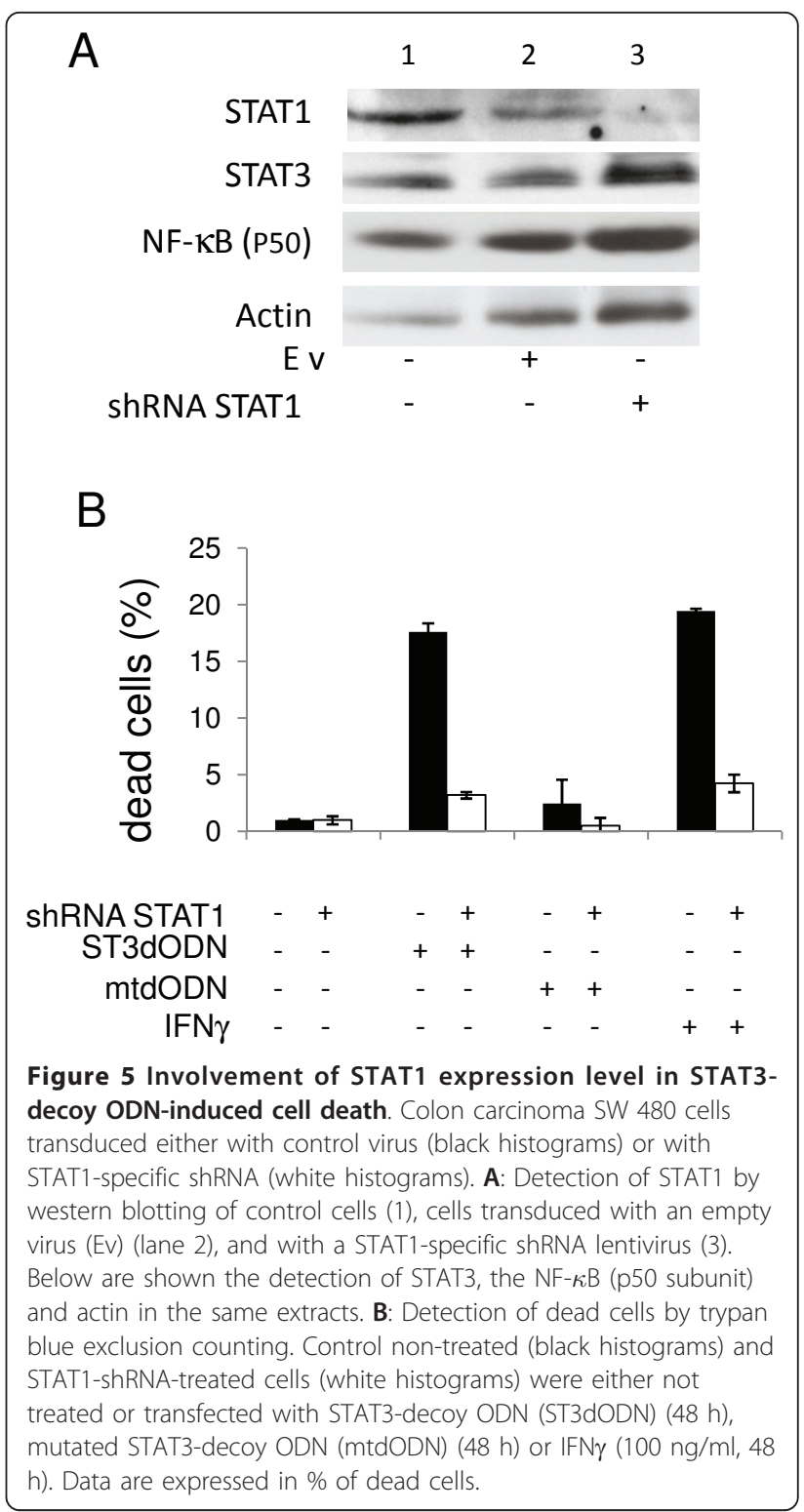

of the mutated STAT3-decoy ODN, but IFN $\gamma$-induced cell death was suppressed (Figure 5B). Thus, STAT1 expression is important for cell death induction by STAT3 inhibitors, in agreement with observations published elsewhere [44], and in line with the notion that STAT1 is a key component of the cellular mechanism leading to cell death $[45,46]$.

Blockage of STAT3 nuclear transfer by STAT3-decoy ODN is overcome by IL-6-mediated activation of STAT3 or increased expression of recombinant STAT3

To evaluate the relevance of STAT3-decoy ODN/ STAT3 interaction in the reduction of nuclear STAT3, cells were transfected with STAT3-decoy ODN and treated with IL-6, and nuclear STAT3 was analyzed. 
Treatment with IL-6 significantly increased the tyrosine phosphorylation of STAT3; inhibition of STAT3 nuclear transfer by STAT3-decoy ODN was partially overcome by this treatment (Figure 6A), suggesting a titrating effect of the increased amount of active STAT3 on STAT3-decoy ODN action. Similarly, overexpression of STAT3 by plasmid transfection of SW 480 cells resulted in a marked increase of STAT3 nuclear localization (Figure 6B, lane 2) and considerably reduced inhibitory effects of STAT3-decoy ODN (lane 5) and Stattic (lane 6). However, when more STAT3-decoy ODN $(4 \mu \mathrm{g})$ was added to STAT3-overexpressing cells, a reduction of nuclear STAT3 was observed (Figure 6C, lane 6). Conversely, in cells transfected with DBD-mutated STAT3, there was no change in nucleo-cytoplasmic distribution after treatment with STAT3-decoy ODN (Figure 6D, lane 6). This emphasizes the notion that a functional DBD is necessary for STAT3-decoy ODN to prevent STAT3 nuclear localization. Cell death was also analyzed to determine whether modifications of STAT3's subcellular localization affected cell fate. Overexpression of STAT3 in SW 480 cells significantly reduced the rate of cell death induced by STAT3-decoy ODN or by Stattic $(5 \mu \mathrm{M})$ (Figure 6E). Combining the cell death data shown in Figure 6E with the amounts of nuclear STAT3 of Figure 6B showed that nuclear accumulation of STAT3 is inversely proportional to cell death (Figure 6F). Overall, these experiments suggest that STAT3decoy ODN-induced cell death results from the inhibition of STAT3 through its entrapment within the cytoplasm.

\section{STAT3-decoy ODN interferes with the cytoplasmic-nuclear shuttling of STAT3}

Nuclear transfer of activated STAT3 through nuclear pores is dependent on nuclear import involving karyopherin/importins, which interact with STAT3's NLS; the NLS located within the DBD being the most efficient in STAT3 $[3,5]$. The activated STAT3 dimer enters the nucleus, binds its DNA targets, and is then released, after which it is dephosphorylated by a nuclear tyrosine phosphatase [7]; inhibition of the phosphatase with vanadate traps STAT3 in the nucleus (shown by increased nuclear phospho-STAT3 in vanadate-treated SW480 cells, see supplemental data 3). The transfer of STAT3 to the cytoplasm depends in part on the export protein CRM1 [47], which can be selectively inhibited by leptomycine B (LMB) [48]. To further characterize the mechanism of action of STAT3-decoy ODN on STAT3 nucleo-cytoplasmic shuttling, the cells were treated with LMB or vanadate. Treatment with LMB (10 $\mathrm{ng} / \mathrm{ml}$ ) increased nuclear STAT3 (Figure 7A, lane 2, and $7 \mathrm{C})$, as previously shown in v-src expressing cells [31] (it also inhibited STAT3 phosphorylation, in agreement with previous results [31], see [additional file 3]). Treatment with vanadate $(100 \mu \mathrm{M})$ or with both LMB and vanadate also increased nuclear STAT3 (Figure 7A, and 7C). Vanadate (Figure 7B, lane 2) and LMB (Figure 7B, lane 3) competed with STAT3-decoy ODN and opposed its action by retaining STAT3 within the nucleus.

Nuclear transfer of activated STAT3 involves karyopherins/importins which interact with the NLS located within the DBD $[3,5]$. To verify the possibility of a competition between karyopherin and STAT3-decoy ODN for STAT3 binding, STAT3 immunoprecipitation and STAT3-decoy ODN pull-downs were compared to one another for their karyopherin content. Karyopherin was detected in the STAT3 immunoprecipitates (Figure 8A, lane 3) and STAT3 was detected in the karyopherin immunoprecipitates (lane 4), but neither of them was detected in the IgG immunoprecipitate control (lane 2). On the other hand, STAT3-decoy ODN-trapped STAT3, detected by treating cells with biotinylated STAT3-decoy ODN (under the conditions shown above to inhibit STAT3 nuclear transfer; see Figure 2A), collected on avidin-coated agarose beads and analyzed by western blotting, contained either no karyopherin or only trace amounts, while clearly containing STAT3 (Figure 8B, lane 2), as previously shown [17]. An identical experiment performed with mutated STAT3-decoy ODN showed practically no detectable STAT3 or karyopherin (not shown). The amount of karyopherin detected in the crude lysates is shown in figures $8 \mathrm{~A}$ (lane 1), and 8B (lane 1). The observations reported here suggest that STAT3-decoy ODN impairs the binding of STAT3 complexes to karyopherin.

\section{Inhibition of STAT3 with STAT3-decoy ODN in SW 480 cells is associated with inhibition of NF- $\kappa$ B}

Experiments were conducted to determine whether the inhibition of STAT3 by STAT3-decoy ODN could indirectly affect NF- $\kappa$ B nuclear translocation, since a functional interaction between STAT3 and NF- $\kappa$ B has been reported in several cellular systems $[21,34,49]$. In the SW 480 cells, Stattic was found to inhibit the nuclear transfer of both STAT3 and NF- $\kappa$ B (not shown), and to inhibit NF- $\kappa$ B activity as measured with a NF- $\kappa$ B-specific reporter plasmid (not shown). STAT3-decoy ODN, but not mutated decoy ODN, markedly reduced NF- $\kappa \mathrm{B}$ nuclear translocation (Figure 9A, lanes 4 and 8). Pulldown experiments with STAT3-decoy ODN also showed higher amounts of NF- $\kappa \mathrm{B}$ in the complex obtained from the nuclear fraction of IL-6-treated cells (Figure 9B, lane 4, and [additional file 4]). TNF- $\alpha$-stimulated nuclear transfer of NF- $\kappa \mathrm{B}$ (Figure 9C, lane 4), which was inhibited by the NF- $\kappa \mathrm{B}$-decoy ODN (not shown), was insensitive to STAT3-decoy ODN (Figure 9C, lane 8); similar results were observed when probing 


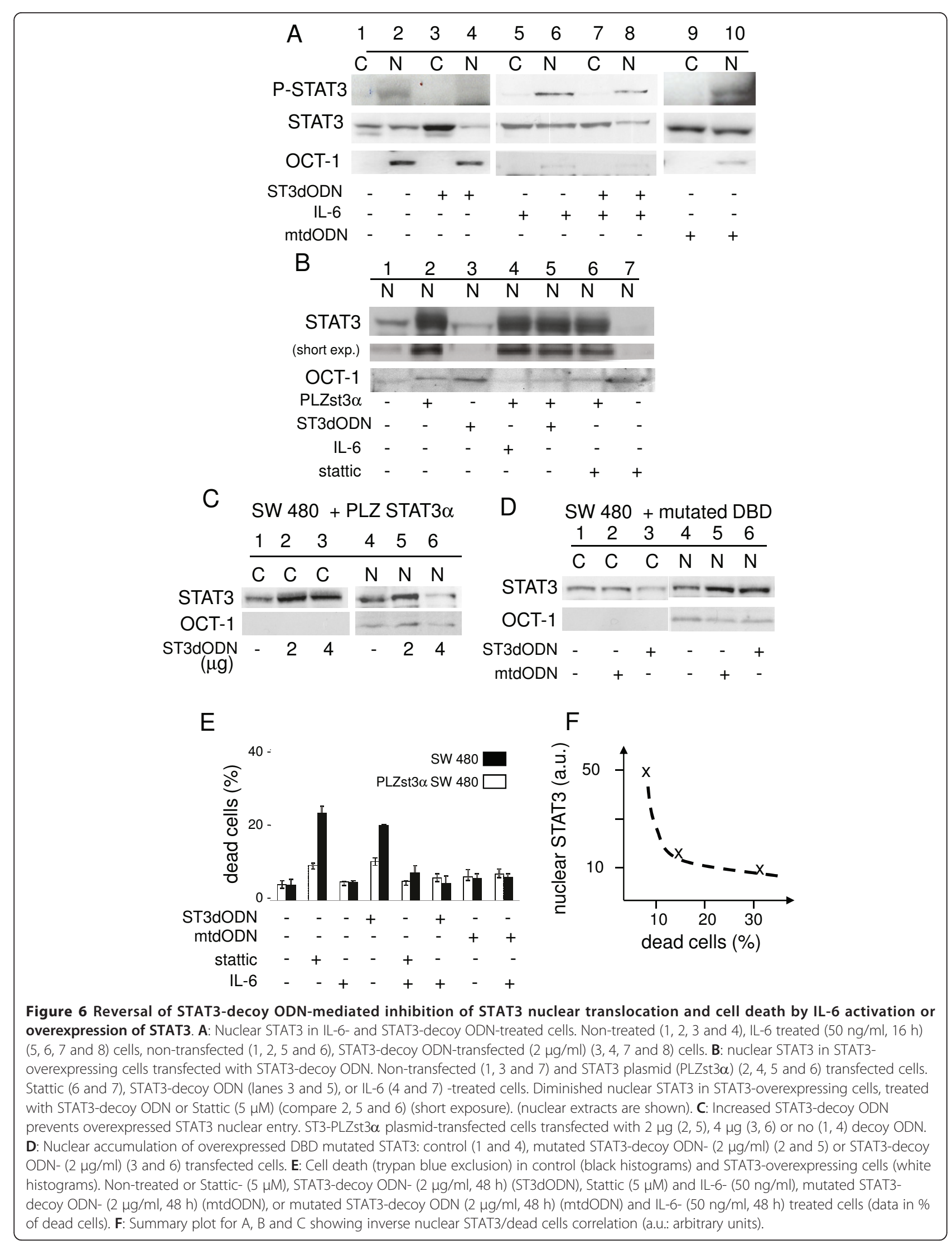




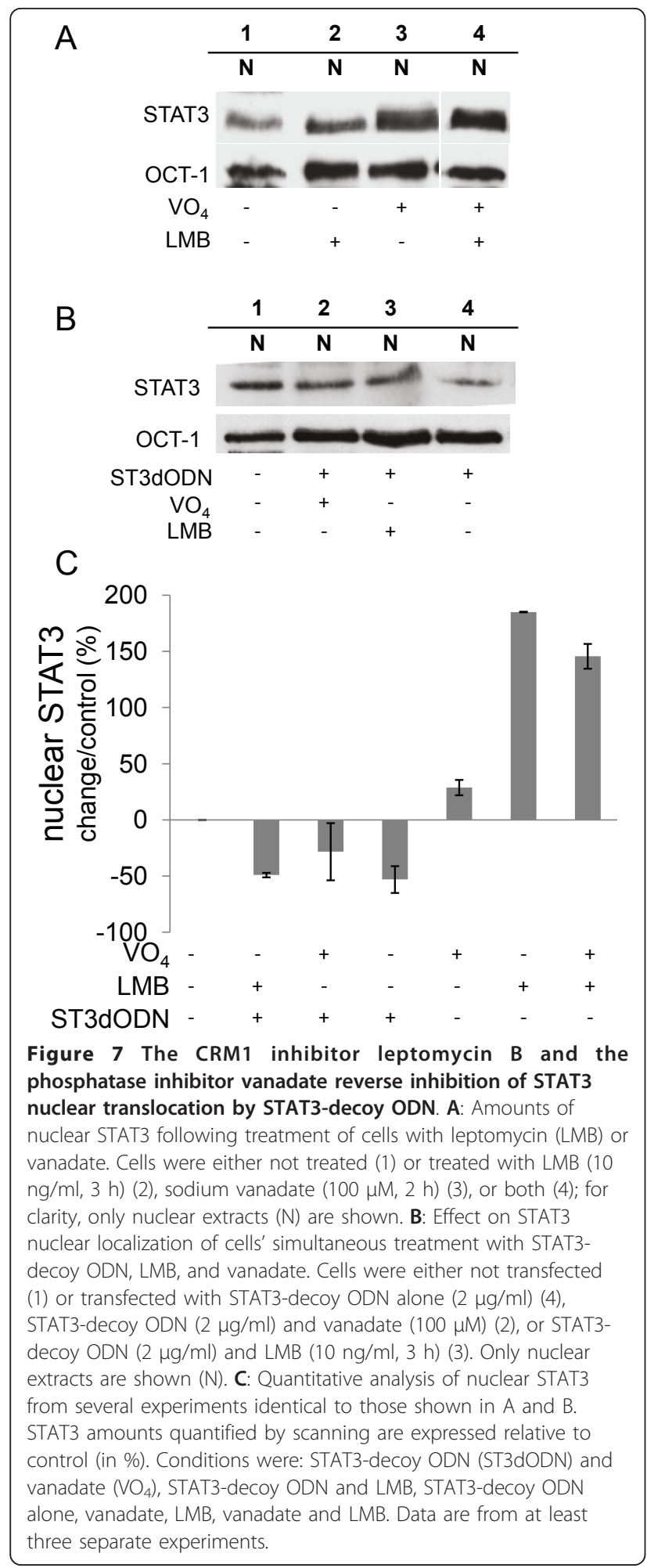

the NF- $\kappa \mathrm{B}$ pull-downs with anti-p65 antibody, except that the basal levels were somewhat higher (Figure 9C). The expression of the direct NF- $\kappa \mathrm{B}$ target $\mathrm{I}-\kappa \mathrm{B}$, as determined by qPCR analysis, was inhibited to $50 \%$ of

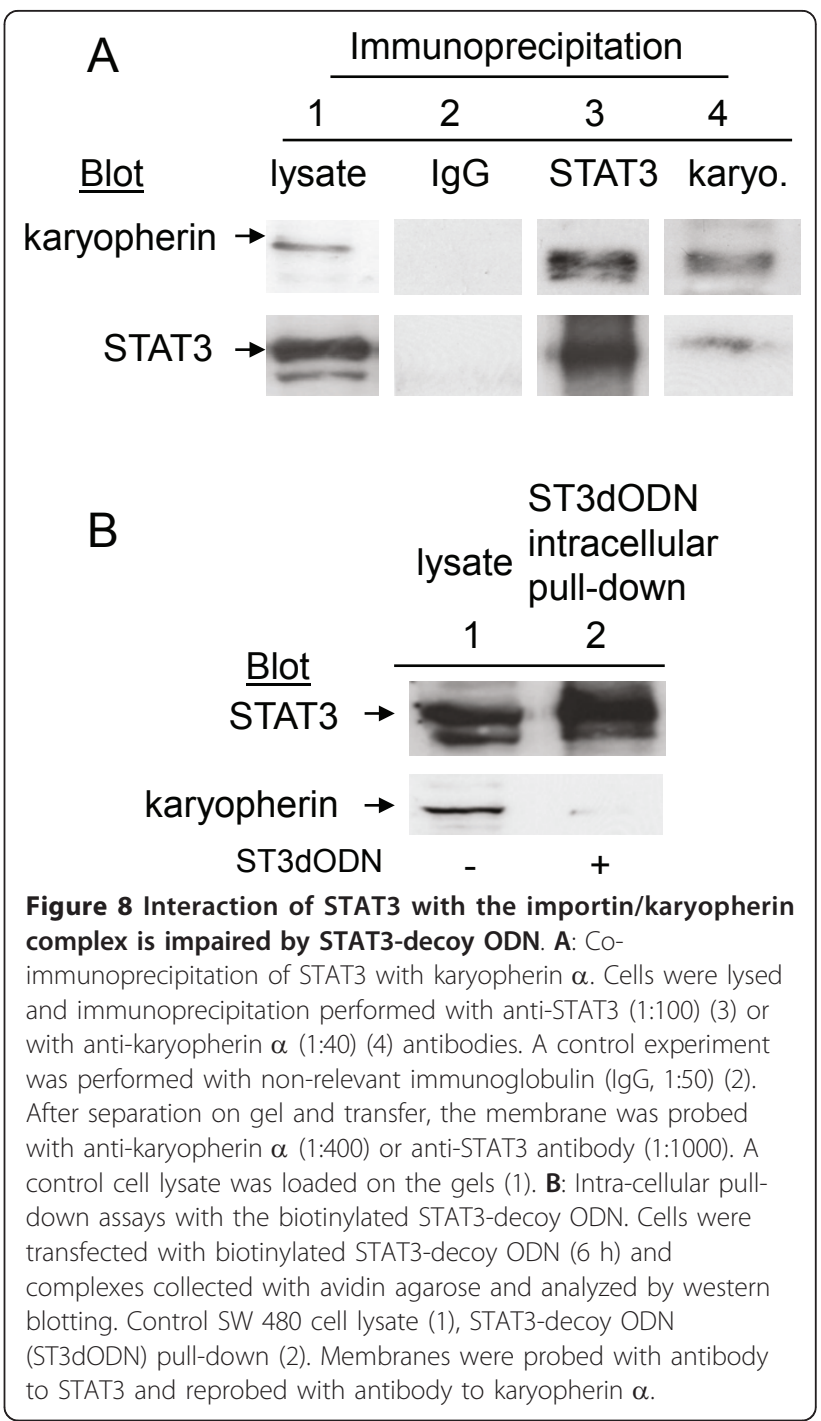

the control level by STAT3-decoy ODN (Figure 9D). However, TNF- $\alpha$-induced I- $\kappa \mathrm{B}$ mRNA remained high in the presence of STAT3-decoy ODN (Figure 9D). On the other hand, the expression of cyclin D1, a STAT3 target gene, was inhibited by STAT3-decoy ODN (Figure 9E). Thus, a decoy ODN targeting STAT3 can inhibit NF- $\kappa$ B indirectly.

\section{Discussion}

Constitutive STAT3 activation is frequently involved in uncontrolled tumor cell proliferation and therefore constitutes a valuable target for anti-tumor therapy $[11,50]$. Decoy oligonucleotides (decoy ODNs) have been shown to efficiently induce cell death in many different cellular systems (see [51] for review) and to have a potential for specific targeting of tumor cells. However, although it is generally assumed that decoy ODNs must enter the nucleus to exert their inhibitory action on the targeted 


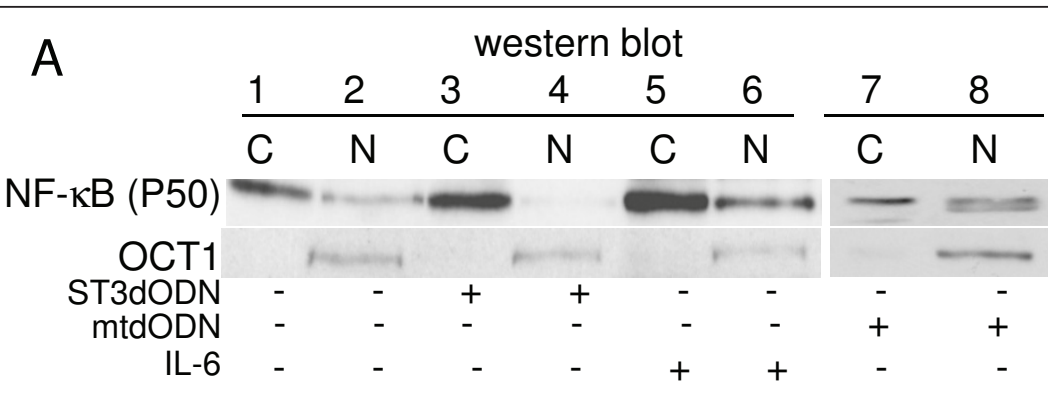

B

\section{ST3dODN pull-down}

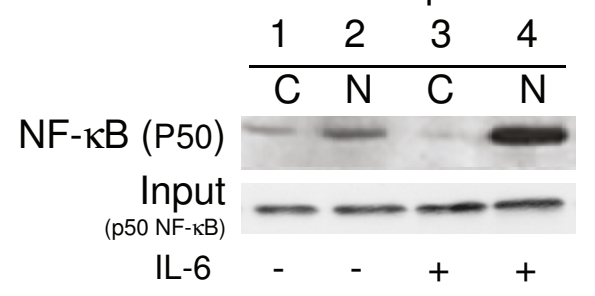

C

NF- $\kappa$ BdODN pull-down

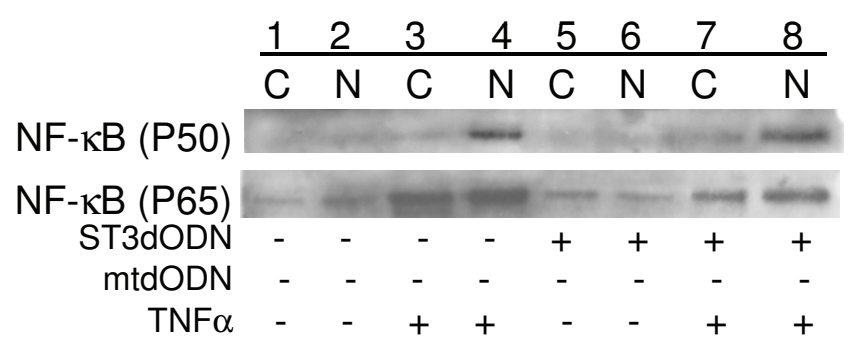

D

$\mathrm{E}$
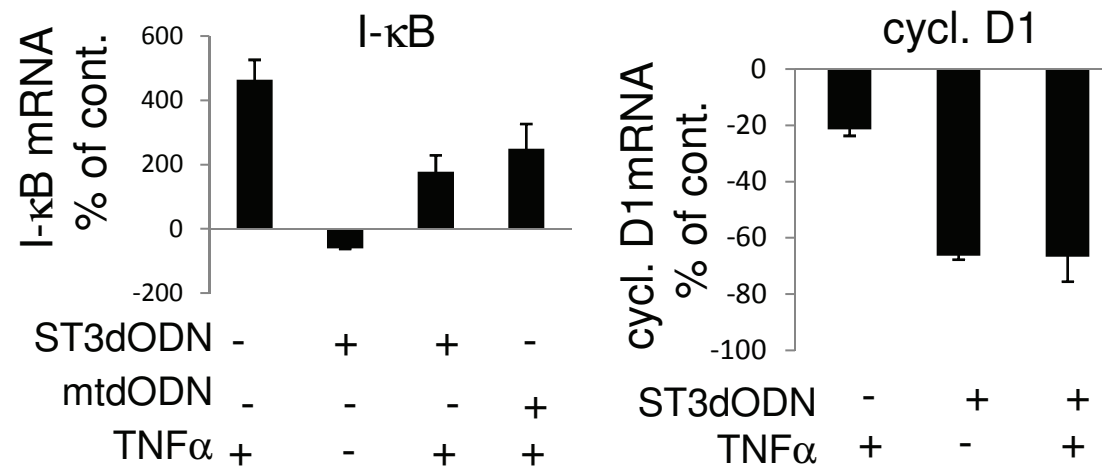

Figure 9 Functional interaction of STAT3 with NF- $\kappa$ B in SW $\mathbf{4 8 0}$ cells. A: NF- $\kappa$ B nuclear transfer in STAT3-decoy ODN-transfected SW 480 cells. Cells were transfected with STAT3-decoy ODN (ST3dODN) $(2 \mu \mathrm{g} / \mathrm{ml})(3$ and 4), IL-6 (50 ng/ml, $16 \mathrm{~h}$ ) (5 and 6), or mutated STAT3-decoy ODN (mtODN) (7 and 8). Controls: 1 and 2. B: Probe of STAT3-decoy ODN pull-down with NF- $\kappa$ B antibody in non-transfected cytoplasm and nuclear fractions ( 1 and 2 ) and in IL-6 (50 ng/ml)-treated cytoplasm and nuclear fractions ( 3 and 4). C: Analysis of NF- $\kappa$ B activity by pull-down assay with NF- $\kappa$ B-decoy ODN following treatment of cells with STAT3-decoy ODN $(2 \mu \mathrm{g} / \mathrm{ml})$. Cells treated with TNF- $\alpha(20 \mathrm{ng} / \mathrm{ml})(3 \mathrm{and} 4)$ transfected with STAT3-decoy ODN $(2 \mu \mathrm{g} / \mathrm{ml}$ ) (lanes 5 and 6 ), treated with both TNF- $\alpha$ and STAT3-decoy ODN (7 and 8), transfected with mutated STAT3-decoy ODN (2 $\mu \mathrm{g} / \mathrm{ml})$ (9 and 10), or with both TNF- $\alpha$ and mutated STAT3-decoy ODN (11 and 12); untreated cells: 1 and 2. Western blotting with NF- $\kappa$ B antibody (p50 or p65 subunits). D: mRNA levels of the NF- $\kappa$ B target $1-\kappa B$ (qPCR) after STAT3-decoy ODN treatment. Cells were not transfected, transfected with STAT3-decoy ODN (ST3dODN) $(2 \mu \mathrm{g} / \mathrm{ml})$, treated with TNF- $\alpha(20 \mathrm{ng} / \mathrm{ml})$, treated with both STAT3decoy ODN and TNF- $\alpha$, or transfected with mutated STAT3-decoy ODN (mtdODN) $(2 \mu \mathrm{g} / \mathrm{ml}$ ) and TNF- $\alpha$. E: mRNA levels of cyclin-D1 (qPCR) after treatment with STAT3-decoy ODN. Cells were not treated, treated with TNF- $\alpha(20 \mathrm{ng} / \mathrm{ml})$, transfected with STAT3-decoy ODN $(2 \mu \mathrm{g} / \mathrm{ml})$, or treated with both TNF- $\alpha$ and STAT3-decoy ODN. Results are expressed as \% of control. 
TF, little is known of their mechanism of action. To study this issue, the SW 480 colon carcinoma tumor cell line was used as a model system. These cells require a basal level of activated STAT3 for survival [17,41], as confirmed here by STAT3-specific siRNA- or Statticinduced cell death. To analyze the impact of a STAT3decoy ODN on the subcellular localization of STAT3 in the colon carcinoma cell line SW 480, a combination of subcellular fractionation, oligonucleotide pull-down and immunofluorescence microscopy was used, in non-stimulated cells in most experiments in order to reproduce physiological conditions as much as possible. The main observations of this study are that: i, the STAT3-decoy ODN interacts with active phospho-STAT3 dimers, ii, this interaction results in the cytoplasmic trapping of phospho-STAT3 and iii, blocked nuclear transfer of active STAT3 by STAT3-decoy ODN results in reduced cyclin D1 (a key target of STAT3) expression and cell death induction. STAT3-decoy ODN was found to interact with activated dimeric STAT3 but not with non-activated STAT3 (see Figure 1A where STAT3, although present in the cytoplasmic fraction, does not interact with the STAT3-decoy ODN and the pull-down assays of Figure 2 where phospho-STAT3 is brought down by the STAT3-decoy ODN but not in the presence of Stattic). The specificity of STAT3 targeting by STAT3-decoy ODN was further evidenced by the absence of any effect on STAT3 nuclear transfer of either a control mutated STAT3-decoy ODN or a decoy NF- $\kappa$ B-ODN. In addition, STAT3-decoy ODN did not prevent the nuclear transfer of DNA binding domain (DBD)-mutated STAT3, indicating that a functional DBD domain is necessary for activated STAT3 to bind STAT3-decoy ODN. Nuclear entry of proteins involves a NLS within the protein's sequence, which allows interaction with components of the nuclear membrane pore complex (NPC). About half of the identified NLS lie within the DBD of proteins. STAT3 contains several NLS $[32,52]$, but its major functional NLS lies within the DBD [3,5]; this dimer-specific NLS appears to be essential for STAT dimer binding to karyopherin/importins [53] which mediate interaction with the NPC. This suggests that STAT3 cytoplasmic trapping by STAT3decoy ODN results from the interaction of the decoy ODN with the DBD domain of a functional STAT3 dimer, thereby masking the NLS and preventing interaction with karyopherin/importins as depicted in Figure 10A. Indeed, STAT3 immunoprecipitation brought down karyopherin $\alpha$, while STAT3-decoy ODN pulldown did not. This observation is in agreement with studies showing that an ODN containing the m67 sequence can displace the interaction of recombinant phospho-STAT1 with recombinant importin $\alpha$ [54]. The observation that STAT3-decoy ODN inhibited only activated STAT3 suggests that it could effectively inhibit STAT3 in cells in which there is basal nucleo-cytoplasmic shuttling of activated STAT3. Constitutive nucleocytoplasmic shuttling of STAT3 has been observed in several cell systems [52], including v-src transformed cells in which STAT3 is activated [31]. Previous immuno-cytochemistry studies have shown that the CRM-1 inhibitor LMB interferes with the nucleo-cytoplasmic shuttling of STAT3, resulting in its nuclear accumulation $[8,31]$ and inhibition of tyrosine phosphorylation [31]. In the present study, LMB increased nuclear localization of STAT3 and prevented the action of STAT3-decoy ODN, reinforcing the view that the latter acts on nucleo-cytoplasmic shuttling. Similar results were obtained with the tyrosine phosphatase inhibitor vanadate, which increased the amount of nuclear STAT3, and also prevented the action of STAT3-decoy ODN, thereby preventing cytoplasmic retention of STAT3. The modification of total STAT3 subcellular distribution induced by STAT3-decoy ODN observed here suggests that STAT3-decoy ODN functions by targeting the nucleo-cytoplasmic traffic itself, as previously suggested [33]. The data also indicate that STAT3decoy ODN impairs the shuttling of active STAT3 dimers only, without interfering with the previously reported constitutive activation-independent nucleocytoplasmic shuttling of non-phosphorylated dimers [32,55,56] (see Figure 10). Non-phosphorylated STAT3 was found to be transcriptionally active [57], but whether it can bind STAT3 consensus sequences is not clear [58]. Thus, in all likelihood, the inhibitory action of STAT3-decoy ODN relies on the constitutive activation of STAT3 in SW 480 cells leading to its nuclear localization. The specific inhibition of the nucleo-cytoplasmic turn-over of STAT3 distinguishes STAT3-decoy ODN from chemicals, such as Stattic [16], that have been designed to prevent STAT3 dimer formation by interacting with the $\mathrm{SH} 2$ domain, subsequently impairing nuclear translocation; and from siRNAs, which target the entire STAT3 protein pool in any cell, disrupting functions that may be unrelated to growth and increasing the chances of side effects.

Cell death and apoptosis depend partly on STAT1dependent effector genes [46,59] (see also [60] for a review). In the present study, the suppression of STAT1 by RNA silencing prevented cell death induction by STAT3-decoy ODN, indicating a critical role for STAT1, independent of IFN $\gamma$ activation, in line with previous observations showing STAT1-dependent IFNindependent cell death [59]; (see also: [61]). However, STAT1 is the major effector of IFN $\gamma$, which is antiproliferative or tumoricidal in several cancer cell types $[62,63]$; although STAT3-decoy ODN has been found to induce tumor cell death in several different cell systems 

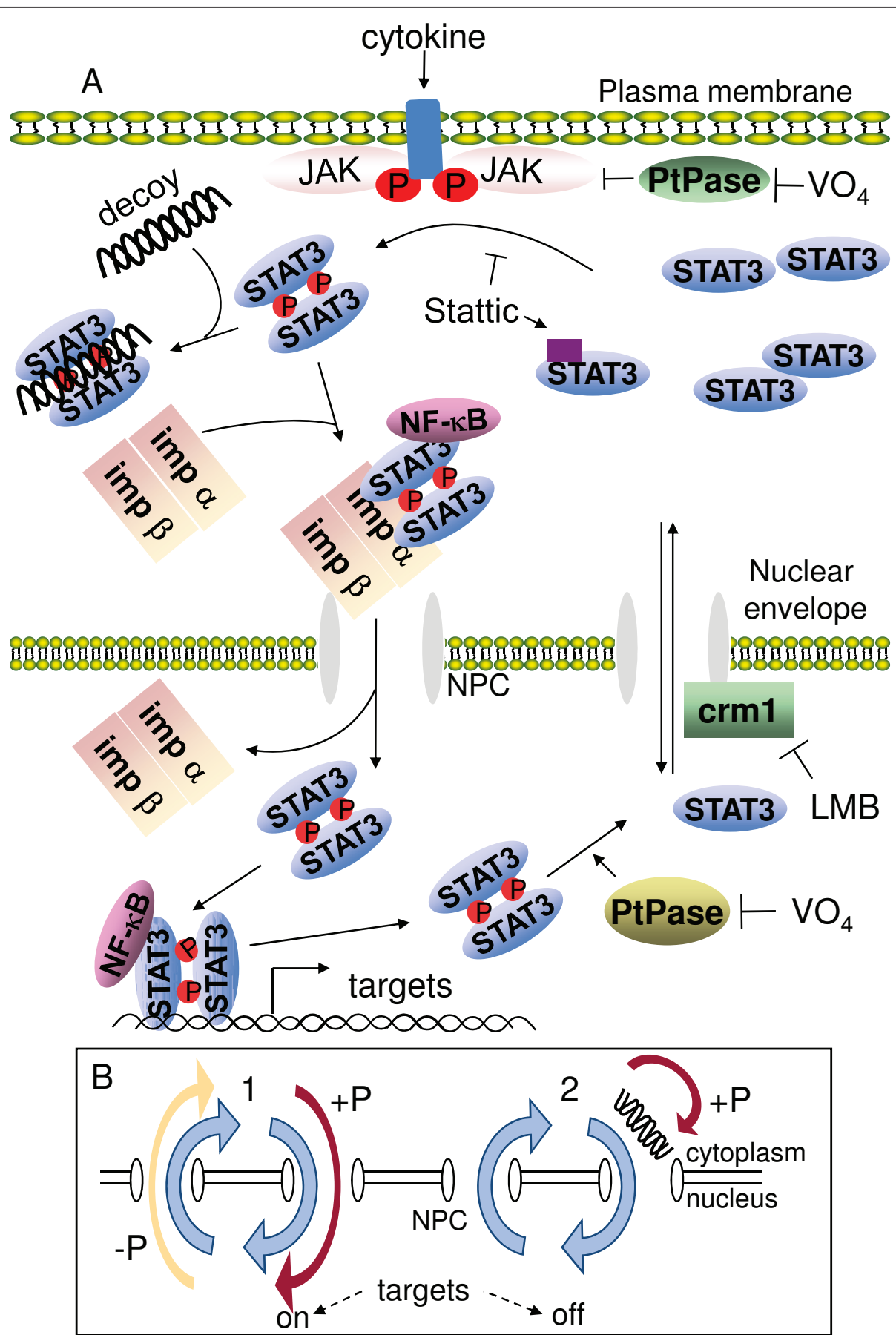

Figure 10 Nucleo-cytoplasmic shuttling of STAT3, and putative mechanism of action of STAT3-decoy ODN. A: Nucleo-cytoplasmic shuttling of activated STAT3. Phosphorylation of STAT3 on tyrosine 705 by the JAK family kinases results in dimerization and interaction with importins (imp), followed by transfer to the nucleus through the nuclear pore complex (NPC). Phospho-STAT3 binds its DNA targets, this is followed by dephosphorylation by a nuclear tyrosine phosphatase. Unphosphorylated STAT3 re-enters the cytoplasm: this depends in part on CRM1, which is inhibited by leptomycin B (LMB). Tyrosine phosphatases which dephosphorylate activated JAKs and phospho-STAT3 are inhibited by sodium vanadate $\left(\mathrm{VO}_{4}\right)$. Stattic interaction with STAT3 monomers prevents dimerization and nuclear entry. STAT3-decoy ODN (decoy) interaction with active phosphorylated STAT3 dimers is suggested to compete with importin, thereby trapping active STAT3 in the cytoplasm. B: Nucleo-cytoplasmic cycling of activated and non-activated STAT3. Non-activated STAT3 cycles in and out of the nucleus in the absence of activation (phosphorylation: $+P$ ) (1, blue arrows). Activated STAT3 enters the nucleus by a transporter-mediated process (1, red arrow) and returns to the cytoplasm following dephosphorylation: -P) (1, yellow arrow). In STAT3-decoy ODN-transfected cells, cycling of non-activated STAT3 is unchanged (2, blue arrows), whereas activated (phosphorylated) STAT3 does not enter the nucleus (2, red arrow). NPC: nuclear pore complex. The scheme in B is adapted from a figure of ref.[3]. 
$[17,22-24]$, it can also inhibit STAT1 $[17,64]$. Despite their opposing biological effects [65], STAT1 and STAT3 form heterodimers whose function is unclear [66]. Thus, despite its efficiency in inducing cell death, and although it has been found to have few side effects when administered to primates [67], suggesting a potential for clinical applications, STAT3-decoy ODN must be optimized so that it can distinguish between STAT3 and STAT1. Work is in progress to try and define the structural constraints that underlie specific recognition of STAT3-decoy ODN by STAT3.

In cancer, STAT3 and NF- $\kappa$ B have been shown to cooperate in promoting cell growth by interacting at different levels of their activating pathways [35]. STAT3 can trap constitutively activated NF- $\kappa$ B within the nucleus of tumor cells [68]. In SW 480 cells, both NF- $\kappa \mathrm{B}$ and STAT3 are activated, suggesting a constitutive interleukin secretory loop, as described for several tumor cell systems (see: [49]). The findings of the present paper indicate that active STAT3 interacts with $\mathrm{NF}-\kappa \mathrm{B}$ in the colon-carcinoma cell line SW 480, as shown by the presence of NF- $\kappa$ B in STAT3-decoy ODN pull-downs and by reduced NF- $\kappa$ B transcriptional activity. Unphosphorylated STAT3 also interacts with NF- $\kappa \mathrm{B}$, but apparently binds $\kappa \mathrm{B}$ sites [57], and may not be recognized by STAT3-decoy ODN for this reason. Thus, by trapping active STAT3 within the cytoplasm, STAT3-decoy ODN can simultaneously trap the fraction of NF- $\kappa \mathrm{B}$ that is associated to active STAT3; this may potentially allow the targeting of a subset of genes that is essential for uncontrolled tumor cell growth.

\section{Conclusions}

STAT3-decoy ODN is an efficient inducer of cell death in the colon-carcinoma cell line SW 480. It is shown here to function by trapping activated STAT3 within the cytoplasm by binding to the active dimer and preventing binding to karyopherin, which is required for the transfer of active STAT3 into the nucleus. STAT3decoy ODN appears to be capable of specifically targeting active STAT3, and not its inactive form. Thus, STAT3-decoy ODN inhibits STAT3 only in cells where STAT3 is activated, such as cancer cells, resulting in cell death without harming healthy cells. Furthermore, the entrapment of STAT3-bound NF- $\kappa$ B adds a new powerful anticancer potential to STAT3-decoy ODN. These results point to the DNA binding domain of STAT3, as well as the process through which activated STAT3 enters the nucleus, as potential sources of active anticancer compounds.

\section{Additional material}

Additional file 1: Subcellular localization of the STAT3-decoy ODN Cells were grown in 8-well plates to a density of 2.104 cells $/ \mathrm{mL}$. When the cells reached $50-60 \%$ confluence, they were transfected with the FITC-labeled (green) STAT3-decoy ODN $(2 \mu \mathrm{g})$ in $150 \mu \mathrm{L}$ of culture medium (DMEM without Fetal Calf Serum) combined to the liposomes (2 $\mu \mathrm{g}$ of cationic lipid). After $6 \mathrm{~h}$ at $37^{\circ} \mathrm{C}$ in a humidified $5 \% \mathrm{CO} 2$ incubator, the cells were placed in fresh FCS-containing medium. After $48 \mathrm{~h}$ the cells were fixed and stained with DAPI to visualize nuclei and examined by fluorescence microscopy (A: nuclei, B: merge, C: FITC-labeled decoy).

Additional file 2: In-cell STAT3-decoy ODN pull-down assays. Cells were transfected with the STAT3-decoy ODN, as described under oligonucleotide transfection (see methods), and then processed by cell lysis and recovery on avidin-Sepharose beads. After extensive washing with binding buffer, complexes were separated on SDS-polyacrylamide (8\%) gel, subjected to immunoblotting using an anti-phospho-STAT3 antibody (Cell Signaling); input was determined by analyzing an aliquot of the initial lysate with STAT3 antibody (Cell Signaling). Results were analyzed by chemiluminescence (LumiGLO, Cell Signaling) and autoradiography (X-Omat $R$, Kodak). In A, cells were either not treated (1) or treated with decoy STAT3-ODN (2). In B, cells were either not treated or treated with $\mathrm{IL}-6(50 \mathrm{ng} / \mathrm{ml})$.

Additional file 3: Effect of leptomycin B and of vanadate on the level of phospho-STAT3. Cells were either not treated $(1,2)$, treated with leptomycin B (LMB) $(5 \mathrm{ng} / \mathrm{ml})(3,4),(10 \mathrm{ng} / \mathrm{ml})(5,6),(15 \mathrm{ng} / \mathrm{ml})(7$, 8) or vanadate $(200 \mu \mathrm{M})(9,10)(500 \mu \mathrm{M})(11,12)$, for $4 \mathrm{~h}$. Cytoplasmic (C) and nuclear extracts $(\mathrm{N})$ (see methods) were analyzed on acrylamide gels and the membranes probed with anti-phospho-STAT3 and anti-Oct-1 antibodies.

Additional file 4: Effect of the STAT3-decoy ODN and of IL-6 on the nuclear localization of the p50 subunit of NF- $\kappa$ B. Cells were either not treated $(1,2)$, treated with STAT3-decoy ODN $(2 \mu \mathrm{g} / \mathrm{ml})(3,4), \mathrm{IL}-6(50$ $\mathrm{ng} / \mathrm{ml})(5,6)$ or both $(7,8)$ for $6 \mathrm{~h}$. Cytoplasmic (C) and nuclear extracts (N) (see methods) were analyzed on acrylamide gels and the membranes probed with anti-p50-NF- $\kappa$ B and anti-Oct-1 antibodies.

\section{Acknowledgements}

We thank Dr. Curt Horvath (Northwestern University, Chicago USA) for the kind gift of DNA-binding mutant STAT3 plasmid, and Dr. David Tabatadze (Zata, Worcester, Mass. USA) for help with oligonucleotide synthesis. IS was supported by a grant from the Association pour la Recherche sur le Cancer (ARC), IN was supported by the Ligue contre le Cancer, and LAK was supported by the Ministère de l'éducation et de la Recherche. This work was funded in part by grants from OSEO (France), the Ligue contre le Cancer (France) and the Ligue contre le Cancer (comité du Val d'Oise).

\section{Author details}

${ }^{1}$ INSERM, Unité 978, Bobigny, France. ' Université Paris 13, UFR SMBH, Bobigny, France. ${ }^{3}$ AP-HP, Hôpital Avicenne, Service de biochimie, Bobigny, France. ${ }^{4}$ AP-HP, Hôpital Avicenne, Service d'hématologie biologique, Bobigny, France. ${ }^{5}$ Moscow State University, Moscow, Russia. ${ }^{6}$ Institut Cochin, Université Paris Descartes, CNRS (UMR 8104), Paris, France. ${ }^{7}$ INSERM, Unité 1016, Paris, France. ${ }^{8}$ Groupe de Vectorisation, UFR SMBH, Université Paris 13, Bobigny, France.

\section{Authors' contributions}

IS carried out the biochemical, molecular, and cell biology studies. VM, FBM, $C R, I N, P O S, D L, L A K$ and SLC carried out part of the experiments. IDF, AC, and NVB contributed essential reagents. IS and RF designed the study and wrote the paper. All authors read and approved the final manuscript.

Received: 25 February 2011 Accepted: 12 April 2011 Published: 12 April 2011 


\section{References}

1. Schindler C, Levy DE, Decker T: JAK-STAT signaling: from interferons to cytokines. J Biol Chem 2007, 282(28): 20059-20063.

2. Silva CM: Role of STATs as downstream signal transducers in Src family kinase-mediated tumorigenesis. Oncogene 2004, 23(48): 8017-8023.

3. Vinkemeier U: Getting the message across, STAT! Design principles of a molecular signaling circuit. J Cell Biol 2004, 167(2): 197-201.

4. Gorlich D: Transport into and out of the cell nucleus. Embo J 1998, 17(10): 2721-2727.

5. Ma J, Zhang T, Novotny-Diermayr $V$, Tan AL, Cao X: A novel sequence in the coiled-coil domain of Stat3 essential for its nuclear translocation. $J$ Biol Chem 2003, 278(31): 29252-29260

6. Frank DA: STAT3 as a central mediator of neoplastic cellular transformation. Cancer Lett 2007, 251(2): 199-210.

7. ten Hoeve J, de Jesus Ibarra-Sanchez M, Fu Y, Zhu W, Tremblay M, David M, Shuai K: Identification of a nuclear Stat1 protein tyrosine phosphatase. Mol Cell Biol 2002, 22(16): 5662-5668.

8. Bhattacharya S, Schindler C: Regulation of Stat3 nuclear export. J Clin Invest 2003, 111(4): 553-559.

9. Bromberg JF: Activation of STAT proteins and growth control. Bioessays 2001, 23(2): 161-169.

10. Bromberg J: Stat proteins and oncogenesis. J Clin Invest 2002, 109(9): 1139-1142.

11. Al Zaid Siddiquee $\mathrm{K}$, Turkson J: STAT3 as a target for inducing apoptosis in solid and hematological tumors. Cell Res 2008, 18(2): 254-267.

12. Bromberg JF, Wrzeszczynska MH, Devgan G, Zhao Y, Pestell RG, Albanese C, Darnell JE: Stat3 as an oncogene. Cell 1999, 98(3): 295-303.

13. Takeda K, Noguchi K, Shi W, Tanaka T, Matsumoto M, Yoshida N, Kishimoto T, Akira S: Targeted disruption of the mouse Stat3 gene leads to early embryonic lethality. Proc Natl Acad Sci USA 1997, 94(8): 3801-3804.

14. Schlessinger K, Levy DE: Malignant transformation but not normal cell growth depends on signal transducer and activator of transcription 3. Cancer Res 2005, 65(13): 5828-5834.

15. Kunnumakkara $A B$, Anand $P$, Aggarwal BB: Curcumin inhibits proliferation invasion, angiogenesis and metastasis of different cancers through interaction with multiple cell signaling proteins. Cancer Lett 2008, 269(2): 199-225.

16. Schust J, Sperl B, Hollis A, Mayer TU, Berg T: Stattic: a small-molecule inhibitor of STAT3 activation and dimerization. Chem Biol 2006, 13(11): 1235-1242.

17. Tadlaoui Hbibi A, Laguillier C, Souissi I, Lesage D, Le Coquil S, Cao A, Metelev V, Baran-Marszak F, Fagard R: Efficient killing of SW480 colon carcinoma cells by a STAT3 hairpin decoy oligodeoxynucleotide. Interference with interferon gamma-STAT1-mediated killing. FEBS Journal 2009, 276: 2505-2515.

18. Tomita N, Ogihara T, Morishita R: Transcription factors as molecular targets: molecular mechanisms of decoy ODN and their design. Curr Drug Targets 2003, 4(8): 603-608.

19. Yue P, Turkson J: Targeting STAT3 in cancer: how successful are we? Expert Opin Investig Drugs 2009, 18(1): 45-56.

20. Son G, limuro Y, Seki E, Hirano T, Kaneda Y, Fujimoto J: Selective inactivation of NF-kappaB in the liver using NF-kappaB decoy suppresses CCl4-induced liver injury and fibrosis. Am J Physiol Gastrointest Liver Physiol 2007, 293(3): G631-639.

21. Laguillier C, Hbibi AT, Baran-Marszak F, Metelev V, Cao A, Cymbalista F, Bogdanov A Jr, Fagard R: Cell death in NF-kappaB-dependent tumour cell lines as a result of NF-kappaB trapping by linker-modified hairpin decoy oligonucleotide. FEBS Lett 2007, 581(6): 1143-1150.

22. Leong PL, Andrews GA, Johnson DE, Dyer KF, Xi S, Mai JC, Robbins PD, Gadiparthi S, Burke NA, Watkins SF, et al: Targeted inhibition of Stat3 with a decoy oligonucleotide abrogates head and neck cancer cell growth. Proc Natl Acad Sci USA 2003, 100(7): 4138-4143.

23. Aggarwal BB, Sethi G, Ahn KS, Sandur SK, Pandey MK, Kunnumakkara AB, Sung B, Ichikawa H: Targeting signal-transducer-and-activator-oftranscription-3 for prevention and therapy of cancer: modern target but ancient solution. Ann N Y Acad Sci 2006, 1091: 151-169.

24. Sun X, Zhang J, Wang L, Tian Z: Growth inhibition of human hepatocellular carcinoma cells by blocking STAT3 activation with decoyODN. Cancer Letters 2008, 262(2): 201-213.

25. Xi S, Gooding WE, Grandis JR: In vivo antitumor efficacy of STAT3 blockade using a transcription factor decoy approach: implications for cancer therapy. Oncogene 2005, 24(6): 970-979.
26. Ehret GB, Reichenbach P, Schindler U, Horvath CM, Fritz S, Nabholz M, Bucher P: DNA binding specificity of different STAT proteins. Comparison of in vitro specificity with natural target sites. J Biol Chem 2001, 276(9): 6675-6688.

27. Tomita T, Takano H, Tomita N, Morishita R, Kaneko M, Shi K, Takahi K, Nakase T, Kaneda Y, Yoshikawa H, et al: Transcription factor decoy for NFkappaB inhibits cytokine and adhesion molecule expressions in synovial cells derived from rheumatoid arthritis. Rheumatology (Oxford) 2000, 39(7): 749-757.

28. Park YG, Nesterova M, Agrawal S, Cho-Chung YS: Dual blockade of cyclic AMP response element- (CRE) and AP-1-directed transcription by CREtranscription factor decoy oligonucleotide. gene-specific inhibition of tumor growth. J Biol Chem 1999, 274(3): 1573-1580.

29. Bene A, Kurten RC, Chambers TC: Subcellular localization as a limiting factor for utilization of decoy oligonucleotides. Nucleic Acids Res 2004, 32(19): e142.

30. Sakaguchi M, Nukui T, Sonegawa H, Murata H, Futami J, Yamada H, Huh $\mathrm{NH}$ : Targeted disruption of transcriptional regulatory function of p53 by a novel efficient method for introducing a decoy oligonucleotide into nuclei. Nucleic Acids Res 2005, 33(9): e88.

31. Herrmann A, Vogt M, Monnigmann M, Clahsen T, Sommer U, Haan S, Poli V, Heinrich PC, Muller-Newen G: Nucleocytoplasmic shuttling of persistently activated STAT3. J Cell Sci 2007, 120(Pt 18): 3249-3261.

32. Liu L, MCBride KM, Reich NC: STAT3 nuclear import is independent of tyrosine phosphorylation and mediated by importin-alpha3. Proc Nat Acad Sci USA 2005, 102(23): 8150-8155.

33. Meyer T, Vinkemeier U: STAT nuclear translocation: potential for pharmacological intervention. Expert Opin Ther Targets 2007, 11(10): 1355-1365.

34. Lee TL, Yeh J, Friedman J, Yan B, Yang X, Yeh NT, Van Waes C, Chen Z: A signal network involving coactivated NF-kappaB and STAT3 and altered p53 modulates BAX/BCL-XL expression and promotes cell survival of head and neck squamous cell carcinomas. Int J Cancer 2008, 122(9): 1987-1998.

35. Grivennikov SI, Karin M: Dangerous liaisons: STAT3 and NF-kappaB collaboration and crosstalk in cancer. Cytokine Growth Factor Rev 2010, 21(1): 11-19.

36. Horvath CM, Wen Z, Darnell JE: A STAT protein domain that determines DNA sequence recognition suggests a novel DNA-binding domain. Genes Dev 1995, 9(8): 984-994.

37. Najjar I, Deglesne PA, Schischmanoff PO, Fabre EE, Boisson-Dupuis S, Nimmerjahn F, Bornkamm GW, Dusanter-Fourt I, Fagard R: STAT1 dependent IgG cell-surface expression in a human B cell line derived from a STAT1-deficient patient. J Leukoc Biol 2010.

38. Fan $Y$, Zhang $Y L$, Wu Y, Zhang W, Wang $Y H$, Cheng ZM, Li H: Inhibition of signal transducer and activator of transcription 3 expression by RNA interference suppresses invasion through inducing anoikis in human colon cancer cells. World J Gastroenterol 2008, 14(3): 428-434

39. Wagner BJ, Hayes TE, Hoban CJ, Cochran BH: The SIF binding element confers sis/PDGF inducibility onto the c-fos promoter. EMBO J 1990, 9(13): 4477-4484.

40. Reynier P, Briane D, Cao A, Lievre N, Naejus R, Bissieres P, Salzmann J Taillandier E: In vitro and in vivo transfection of melanoma cells B16-F10 mediated by cholesterol-based cationic liposomes. J Drug Target 2002, 10(7): 557-566

41. Lin Q, Lai R, Chirieac LR, Li C, Thomazy VA, Grammatikakis I, Rassidakis GZ Zhang W, Fujio Y, Kunisada $K$, et al: Constitutive activation of JAK3/STAT3 in colon carcinoma tumors and cell lines: inhibition of JAK3/STAT3 signaling induces apoptosis and cell cycle arrest of colon carcinoma cells. Am J Pathol 2005, 167(4): 969-980.

42. Evans MK, Yu CR, Lohani A, Mahdi RM, Liu X, Trzeciak AR, Egwuagu CE: Expression of SOCS1 and SOCS3 genes is differentially regulated in breast cancer cells in response to proinflammatory cytokine and growth factor signals. Oncogene 2007, 26(13): 1941-1948.

43. Gu TL, Goss VL, Reeves C, Popova L, Nardone J, Macneill J, Walters DK, Wang Y, Rush J, Comb MJ, et al: Phosphotyrosine profiling identifies the KG-1 cell line as a model for the study of FGFR1 fusions in acute myeloid leukemia. Blood 2006, 108(13): 4202-4204

44. Shim SH, Sung MW, Park SW, Heo DS: Absence of STAT1 disturbs the anticancer effect induced by STAT3 inhibition in head and neck carcinoma cell lines. Int J Mol Med 2009, 23(6): 805-810. 
45. Lee KY, Anderson E, Madani K, Rosen GD: Loss of STAT1 expression confers resistance to IFN-gamma-induced apoptosis in ME180 cells. FEBS Lett 1999, 459(3): 323-326.

46. Thomas M, Finnegan CE, Rogers KM, Purcell JW, Trimble A, Johnston PG, Boland MP: STAT1: a modulator of chemotherapy-induced apoptosis. Cancer Res 2004, 64(22): 8357-8364.

47. Meyer T, Hendry L, Begitt A, John S, Vinkemeier U: A single residue modulates tyrosine dephosphorylation, oligomerization, and nuclear accumulation of stat transcription factors. J Biol Chem 2004, 279(18): 18998-19007.

48. Kudo N, Wolff B, Sekimoto T, Schreiner EP, Yoneda Y, Yanagida M Horinouchi S, Yoshida M: Leptomycin B inhibition of signal-mediated nuclear export by direct binding to CRM1. Exp Cell Res 1998, 242(2): 540-547.

49. Bollrath J, Greten FR: IKK/NF-kappaB and STAT3 pathways: central signalling hubs in inflammation-mediated tumour promotion and metastasis. EMBO Rep 2009, 10(12): 1314-1319.

50. Fletcher S, Turkson J, Gunning PT: Molecular approaches towards the inhibition of the signal transducer and activator of transcription 3 (Stat3) protein. ChemMedChem 2008, 3(8): 1159-1168.

51. Jing N, Tweardy DJ: Targeting Stat3 in cancer therapy. Anticancer Drugs 2005, 16(6): 601-607.

52. Reich NC, Liu L: Tracking STAT nuclear traffic. Nat Rev Immunol 2006, 6(8): 602-612.

53. Ma J, Cao X: Regulation of Stat3 nuclear import by importin alpha5 and importin alpha7 via two different functional sequence elements. Cell Signal 2006, 18(8): 1117-1126.

54. Nardozzi J, Wenta N, Yasuhara N, Vinkemeier U, Cingolani G: Molecular basis for the recognition of phosphorylated STAT1 by importin alpha5. J Mol Biol 2010, 402(1): 83-100

55. Pranada AL, Metz S, Herrmann A, Heinrich PC, Muller-Newen G: Real time analysis of STAT3 nucleocytoplasmic shuttling. J Biol Chem 2004, 279(15): 15114-15123.

56. Marg A, Shan Y, Meyer T, Meissner T, Brandenburg M, Vinkemeier U: Nucleocytoplasmic shuttling by nucleoporins Nup153 and Nup214 and CRM1-dependent nuclear export control the subcellular distribution of latent Stat1. J Cell Biol 2004, 165(6): 823-833.

57. Yang J, Liao X, Agarwal MK, Barnes L, Auron PE, Stark GR: Unphosphorylated STAT3 accumulates in response to IL-6 and activates transcription by binding to NFkappaB. Genes Dev 2007, 21(11): 1396-1408.

58. Yang J, Stark GR: Roles of unphosphorylated STATs in signaling. Cell Res 2008, 18(4): 443-451.

59. Kumar A, Commane M, Flickinger TW, Horvath CM, Stark GR: Defective TNF-alpha-induced apoptosis in STAT1-null cells due to low constitutive levels of caspases. Science 1997, 278(5343): 1630-1632.

60. Najjar I, Fagard R: STAT1 and pathogens, not a friendly relationship. Biochimie 2010, 92: 425-444.

61. Schindler C: STATs as activators of apoptosis. Trends Cell Biol 1998, 8(3) 97-98.

62. Wall L, Burke F, Smyth JF, Balkwill F: The anti-proliferative activity of interferon-gamma on ovarian cancer: in vitro and in vivo. Gynecol Oncol 2003, 88(1 Pt 2): S149-151.

63. Labeur M, Refojo D, Wolfel B, Stalla J, Vargas V, Theodoropoulou M, Buchfelder M, Paez-Pereda M, Arzt E, Stalla GK: Interferon-gamma inhibits cellular proliferation and ACTH production in corticotroph tumor cells through a novel janus kinases-signal transducer and activator of transcription 1/nuclear factor-kappa B inhibitory signaling pathway. J Endocrinol 2008, 199(2): 177-189.

64. Wagner AH, Wittjen I, Stojanovic T, Middel P, Meingassner JG, Hecker M: Signal transducer and activator of transcription 1 decoy oligodeoxynucleotide suppression of contact hypersensitivity. J Allergy Clin Immunol 2008, 121(1): 158-165, e155.

65. Bromberg JF, Horvath CM, Wen Z, Schreiber RD, Darnell JE: Transcriptionally active Stat 1 is required for the antiproliferative effects of both interferon alpha and interferon gamma. Proc Natl Acad Sci USA 1996, 93(15): 7673-7678.

66. Regis G, Pensa S, Boselli D, Novelli F, Poli V: Ups and downs: The STAT1: STAT3 seesaw of Interferon and gp130 receptor signalling. Semin Cell Dev Biol 2008.

67. Sen M, Tosca PJ, Zwayer C, Ryan MJ, Johnson JD, Knostman KA, Giclas PC, Peggins JO, Tomaszewski JE, McMurray TP, et al: Lack of toxicity of a
STAT3 decoy oligonucleotide. Cancer Chemother Pharmacol 2009, 63(6): 983-995.

68. Lee H, Herrmann A, Deng JH, Kujawski M, Niu G, Li Z, Forman S, Jove R, Pardoll DM, Yu H: Persistently activated Stat3 maintains constitutive NFkappaB activity in tumors. Cancer Cell 2009, 15(4): 283-293.

\section{doi:10.1186/1471-2121-12-14}

Cite this article as: Souissi et al:: A STAT3-decoy oligonucleotide induces cell death in a human colorectal carcinoma cell line by blocking nuclear transfer of STAT3 and STAT3-bound NF- $\kappa$ B. BMC Cell Biology 2011 12:14

\section{Submit your next manuscript to BioMed Central and take full advantage of:}

- Convenient online submission

- Thorough peer review

- No space constraints or color figure charges

- Immediate publication on acceptance

- Inclusion in PubMed, CAS, Scopus and Google Scholar

- Research which is freely available for redistribution 